ISSN 0819-2642

ISBN 9780734040046

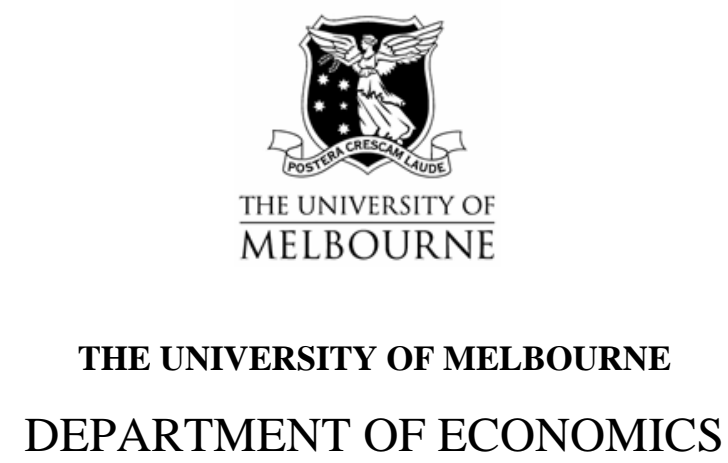

RESEARCH PAPER NUMBER 1038

April 2008

Optimal Sharing Strategies in Dynamic Games of Research and Development

by

Nisvan Erkal \& Deborah Minehart

Department of Economics

The University of Melbourne

Melbourne Victoria 3010

Australia. 


\title{
Optimal Sharing Strategies in Dynamic Games of Research and Development ${ }^{1}$
}

\author{
Nisvan Erkal ${ }^{2}$ and Deborah Minehart ${ }^{3}$ \\ April 2008 \\ The views expressed do not purport to represent the views of \\ the United States Department of Justice.
}

\footnotetext{
${ }^{1}$ We are grateful to Sue Majewski, John Rust, Suzanne Scotchmer, and especially John Conlon and Ethan Ligon for their comments. We also would like to thank conference participants at AEA Annual Meetings (2007), NASM (2007), ESAM (2006), Midwest Economic Theory Meetings (2006), SAET (2005), IIOC (2005), and seminar participants at Case Western Reserve University, U.S. Department of Justice, University of Adelaide, University of Arkansas, University of California-Berkeley, University of Colorado-Boulder, University of Concordia, University of Melbourne, and University of Missouri-Columbia for their comments. In the initial stages of this project, we have benefited from conversations with Eser Kandogan, Ben Shneiderman, and members of the Research Division of IBM. We thank Christian Roessler for his help with the numerical analysis. Nisvan Erkal thanks the Faculty of Economics and Commerce, University of Melbourne for its financial support.

${ }^{2}$ Department of Economics, University of Melbourne, Victoria 3010, Australia. n.erkal@unimelb.edu.au.

${ }^{3}$ United States Department of Justice, Washington, D.C. 20530, USA.
} 


\begin{abstract}
This paper builds a theoretical foundation for the dynamics of knowledge sharing in private industry. In practice, research and development projects can take years or even decades to complete. We model an uncertain research process, where research projects consist of multiple sequential steps. We ask how the incentives to license intermediate steps to rivals change over time as the research project approaches maturity and the uncertainty that the firms face decreases. Such a dynamic approach allows us to analyze the interaction between how close the firms are to product market competition and how intense that competition is. If product market competition is relatively moderate, the lagging firm is expected never to drop out and the incentives to share intermediate research outcomes decreases monotonically with progress. However, if product market competition is relatively intense, the incentives to share may increase with progress. These results illustrate under what circumstances it is necessary to have policies aimed at encouraging cooperation in $R \& D$ and when such policies should be directed towards early vs. later stage research.
\end{abstract}

JEL Codes: L24,O30,D81

Keywords: Multi-stage R\&D; innovation; knowledge sharing; licensing; dynamic games. 


\section{Introduction}

This paper builds a theoretical foundation for the dynamics of knowledge sharing in private industry. As evidenced by the substantial evidence on licensing, research alliances and joint ventures, knowledge sharing arrangements are a central way in which firms acquire technological knowledge. From a social welfare perspective, sharing of research outcomes is desirable because it results in less duplication. Since the 1980s, governments in the US and Europe have actively promoted joint $\mathrm{R} \& \mathrm{D}$ projects through subsidies, tolerant antitrust treatment, and government-industry partnerships. ${ }^{1}$ At the same time, economics research has studied the private and social incentives to have knowledge sharing arrangements, focusing on issues of appropriability and spillovers. However, none of these studies has focused on the basic dynamics of private sharing incentives. Research projects in industries such as biotechnology and computers can take years or even decades to complete. Over such long time horizons, there is considerable scope for the sharing strategies of firms to change. Firms may decide to share some intermediate steps, but not all of their research outcomes. For example, Oxley and Sampson (2004) show that direct competitors choose to limit the scope of their alliances to activities which can be considered to be further away from the product market. ${ }^{2}$ Focusing on the dynamics of research, we ask how the incentives to license research outcomes to rivals change over time as a research project approaches maturity.

A question central to the policy debate as well as the study of knowledge sharing arrangements is the impact of competition on cooperation. This is because in many cases, the most suitable research partner for a firm may be one of its competitors. However, such sharing poses especially difficult challenges because they may result in a reduction in the commercial value of the firms' R\&D efforts. Hence, it is important to determine how close profit-driven firms come

\footnotetext{
${ }^{1}$ For example, in the US, the National Cooperative Research and Production Act (NCRPA) of 1993 provides that research and production joint ventures be subject to a 'rule of reason' analysis instead of a per se prohibition in antitrust litigation. In the EU, the Commission Regulation (EC) No 2659/2000 (the EU Regulation) provides for a block exemption from antitrust laws for RJVs, provided that they satisfy certain market share restrictions and allow all joint venture participants to access the outcomes of the research.

${ }^{2}$ Oxley and Sampson (2004) base their study on a sample of $R \& D$ alliances involving companies in the electronics and telecommunications equipment industries. They define the scope of alliances in terms of R\&D, manufacturing and marketing activities, and show that competitors are averse to adding joint manufacturing and marketing activities to their R\&D collaborations. In a study of biotechnology alliances, Lerner and Merges (1998) find that while in a few cases the alliances covered technologies well along the way to regulatory approval, in most cases they were arranged at the earliest stages of research (prior to animal studies, clinical trials and regulatory approval).
} 
to maximizing welfare. A dynamic perspective allows us to analyze the impact of competition on cooperation in two different ways. We can analyze the impact of both how close the firms are to product market competition and how intense that competition is. Our results reveal an interesting interaction between these two factors.

From a dynamic perspective, the process of research is generally characterized by a high level of uncertainty in the beginning. For example, at the outset of a research on a new medical drug, the expected success rate may be as low as $2 \%$ and the expected time to market may be more than a decade. ${ }^{3}$ In such environments, progress in research can be described as a decrease in the level of uncertainty that researchers face. By the time a new drug is a few years from market, there is far less uncertainty about its chance of success and value than at the outset. One of the novel aspects of this project is to focus on the role uncertainty plays in the decisions to share knowledge and to analyze how firms' incentives to share research outcomes change during a research process as the level of uncertainty they face decreases. We show that the impact of uncertainty on firms' sharing incentives depends on the intensity of product market competition.

We assume that research projects consist of several sequential steps. Researchers cannot proceed to the next step before successfully completing the prior step. Moreover, they cannot earn any profits before completing all steps of the project. An important feature of the model is that we assume the different steps of research are symmetric in all respects except in regards to how far away they are from the end of the project. That is, the options and technology available to the firms are the same in all steps of the research process. We deliberately assume that there are no spillovers in research. ${ }^{4}$ It has been stressed in the literature that firms may have higher spillover rates and bigger appropriability problems in earlier stages of research than in later stages of research. ${ }^{5}$ Although the rate of spillovers may shape the dynamics of sharing, we show that this is not the only factor that matters. Assuming that there are no spillovers between the research efforts of different firms allows us to focus on the role uncertainty plays in knowledge sharing.

\footnotetext{
${ }^{3}$ See Northrup (2005).

${ }^{4}$ In the literature on research joint ventures, knowledge spillovers are stated as one of the most important reasons for rival firms to agree to share knowledge.

${ }^{5}$ See, for example, Katz (1986), Katz and Ordover (1990), and Vonortas (1994).
} 
We assume that firms are informed about the progress of their rivals and make joint sharing decisions after each success. In a dynamic R\&D process, firms' incentives to share change as their positions in the race change for two reasons. First, the probability that the firms will survive to be rivals in the product market changes with progress. Second, the ability of the leading firm to earn monopoly profits depends on the progress the firms make during the research process. Because sharing decreases the lead of one firm, it reduces the expected profits that the leader derives from finishing the race first and being a monopolist for some period of time. This cost may be even greater if, but for the sharing, the lagging firm would drop out of the race.

The results reveal that the nature of the sharing dynamics depends critically on whether product market competition allows for the co-existence of competing firms. If duopoly profits are relatively high, firms that are lagging in the research phase would pursue duopoly profits rather than exiting. In this case, the incentives to share intermediate research outcomes decreases monotonically with progress. However, if duopoly profits are relatively low, a lagging firm exits the race once it falls behind (e.g., as in a winner-take-all-market). In this case, the incentives to share intermediate research outcomes may be weakest early on.

These results have important implications for policy-making in innovation environments. They show that the design of optimal knowledge sharing policy should be sensitive to the dynamic sharing patterns which would emerge in the absence of such policy. What is needed to encourage sharing in early stages of an innovation may be different from what is needed to encourage sharing in later stages. Moreover, whether policies should be optimally directed towards early stage or later stage research may depend on the particular industry because of differences in the intensity of competition.

As mentioned above, the impact of competition on cooperation in $R \& D$ has also been the focus of many papers in the economics literature. These papers have mainly studied firms' incentives to share research outcomes at one point in time, either before the start of research, as in the case of research joint ventures, or after the development of a technology, as in the case of licensing. ${ }^{6}$ A general result in these papers is that the intensity of product market competition

\footnotetext{
${ }^{6}$ See, for example, Kamien (1992) on licensing, and Katz (1986), D'Aspremont and Jacquemin (1988) and Kamien, Muller and Zang (1992) on research joint ventures. Patenting and informal sharing between employees of firms are two other methods through which knowledge may be disseminated between firms. See, for example,
} 
decreases the incentives to cooperate. ${ }^{7}$ We contribute to this literature by focusing on the dynamics of sharing.

In addition to contributing to the literature on knowledge sharing, this paper is also related to the literature on how firms' optimal strategies change over time in a dynamic model of R\&D. In this literature, Grossman and Shapiro (1986 and 1987) analyze how firms vary their research efforts over the course of a research project. In an infinite-period race, Cabral (2003) allows firms to choose between two research paths with different levels of riskiness. He shows that the leader chooses a safe technology and the laggard chooses a risky one. Judd (2003) shows that there is excessive risk-taking by innovators.

The paper proceeds as follows. In the next section, we describe the set-up and explain, as a benchmark, what happens if the firms are allowed to collude in the product market. In section 3, we define the monotonicity property which we use in our characterization of the sharing dynamics under rivalry. In section 4 , we analyze the effect of competition on the dynamic sharing incentives of firms in a model with ex-post sharing contracts and two research steps. The case of $N$ research steps is considered in section 5 . In sections 6 and 7, we discuss extensions of our basic model with asymmetric firms and patenting of research outcomes, respectively. We conclude in section 8 .

\section{Model}

Since we are interested in the effect of competition on firms' incentives to share, we consider an environment with two firms, $i=1,2$, which invest in a research project. On completion of the project, a firm can produce output in a product market. We will consider Markov Perfect Equilibria (MPE), where each firm maximizes its discounted expected continuation payoff given the Markov strategy of the other firm. Before describing the payoffs and the MPE, we first give an overview of the research and production phases.

\footnotetext{
Scotchmer and Green (1990) on early innovators' incentives to patent and Severinov (2001) on informal sharing between employees.

${ }^{7}$ For example, Choi (1993) shows that competing firms will cooperate if the level of spillovers are sufficiently high. Wang (2002) shows that licensing between competitors will take place if they produce sufficiently differentiated products. Empirical evidence suggests that firms do take measures to avoid opportunistic behavior when they are collaborating with their competitors. For example, Majewski (2004) shows that direct competitors are more likely to outsource their collaborative R\&D. Oxley and Sampson (2004) show that direct competitors choose to limit the scope of alliance activities.
} 


\subsection{Research Environment}

To capture the idea of progress, we assume that a research project has $N$ distinct steps of equal difficulty. Hence, we assume that the firms divide the research project into different steps and that each firm defines the steps in the same way. A firm cannot start to work on the next step before completing the prior step, and all steps of the project need to be completed successfully before a firm can produce output.

There is no difference between the steps in terms of the technology or the options available to the firms. This is because we seek to derive endogenous differences in the research phases that result from the dynamics in the decisions made by the firms. A basic intuition is that as firms approach the end of the research process, their decisions might increasingly reflect the impending rivalry.

We assume that each firm operates an independent research facility. We model research activity using a Poisson discovery process. Time is continuous, and the firms share a common discount rate $r$. To conduct research, a firm must incur a flow cost $c$ per unit of time. ${ }^{8}$ Investment provides a stochastic time of success that is exponentially distributed with hazard rate $\alpha$. This implies that at each instant of time, the probability that the firm completes a step is $\alpha$. After completing a step, a firm can immediately begin research on the next step. For a firm which has not yet completed the project, a decision not to invest the flow $\operatorname{cost} c$ is assumed to be irreversible and equivalent to dropping out of the game.

When one firm (the leading firm) successfully completes a stage of research before the other firm (the lagging firm) does, we assume that the leading firm can share this knowledge with the lagging firm and thereby save the lagging firm from having to continue to invest to complete the stage. From the point of view of social efficiency, such sharing will always be efficient because it prevents resources from being spent to duplicate research results. There are a variety of ways to model the sharing process. We consider ex post sharing or licensing, where the leading firm shares its result with the lagging firm in exchange for a licensing fee. Sharing can occur instantaneously whenever one firm has completed more stages of research than the other. The

\footnotetext{
${ }^{8}$ We do not allow the firms to choose continuous levels of research effort. This assumption can be motivated by presuming a fixed amount of effort that each firm can exert, which is determined by the capacity of its $R \& D$ division. As an example, Khanna and Iansiti (1997) explain that given the highly specialized nature of the R\&D involved in designing state-of-the-art mainframe computers, firms in this industry find it very expensive to increase the number of researchers available to them.
} 
leader makes a take-it-or-leave-it offer to the lagging firm. If the lagging firm accepts the offer, he pays the licensing fee to the leader who then shares one step of research. After the sharing takes place, each firm that is not yet done with the project decides whether or not to invest.

Regarding the information structure, we assume that the lagging firm cannot observe the technical content of the rival's research without explicit sharing. ${ }^{9}$ In this sense, there are no technological spillovers. Everything else in the game is common knowledge. In particular, firms observe whether their rival is conducting research as well as whether the rival has a success. Third parties such as courts also observe this information and can enforce the licensing contracts.

\subsection{Product Market Competition}

After a firm completes all stages of the research process, it can participate in the product market. The firms produce goods that may be either homogeneous or differentiated, and that they compete as duopolists in the product market. ${ }^{10}$ We represent the product market competition in the following reduced form way.

If both firms have completed the research project, they compete as duopolists and each earns a flow profit of $\pi^{D} \geq 0$ forever. If only one firm has completed the research project, the firm earns a monopoly flow profit of $\pi^{M}>0$ as long as the other firm does not produce output. Here, $\pi^{M}>\pi^{D}$. As a benchmark, we will consider the case that the firms make production decisions to maximize their joint profits in the product market. This results in a joint flow profit of $\pi^{J}$ where $\pi^{J} \geq 2 \pi^{D}$ and $\pi^{J} \geq \pi^{M}$. We use the notation $\widetilde{\pi}^{D}=\frac{\pi^{D}}{r}, \widetilde{\pi}^{M}=\frac{\pi^{M}}{r}$, and $\tilde{\pi}^{J}=\frac{\pi^{J}}{r}$.

These payoffs are sufficiently flexible to capture various models of product competition. For example, if the firms produce homogeneous products and compete as Bertrand or Cournot competitors, then $\pi^{J}=\pi^{M}>2 \pi^{D}$. If the firms produce differentiated products, then $\pi^{J}>\pi^{M}$ and the relationship between $\pi^{M}$ and $2 \pi^{D}$ will depend on the degree of product differentiation

\footnotetext{
${ }^{9}$ Alternatively, we could assume that research results can be copied, but successful firms win immediate patents. A leading firm could then prevent a lagging firm from copying its research by enforcing its patent. If the patent does not prevent the rival from developing a non-infringing technology at the same flow cost $c$ and with the same hazard rate, then the formal set up would be equivalent to ours. We consider the case when patenting changes the research cost of the lagging firm in section 7 .

${ }^{10}$ We assume that the firms conduct the research to solve the same technical problem. However, unmodelled differences in production technologies can still lead them to produce differentiated products.
} 
that exists between the products. For low levels of product differentiation, $\pi^{M}>2 \pi^{D}$; for high levels of product differentiation, $\pi^{M} \leq 2 \pi^{D} \cdot 11$

As an example, consider a demand function of the type $q_{i}=\left(a(1-\gamma)-p_{i}+\gamma p_{j}\right) /\left(1-\gamma^{2}\right)$, where $0<\gamma<1$ so that the products are substitutes. ${ }^{12}$ The goods are less differentiated the higher is $\gamma$. It is possible to show that $\pi^{M} \leq 2 \pi^{D}$ if and only if $\gamma$ is sufficiently small.

To denote the space for technology and profit parameters, we use $\Omega=\left\{\boldsymbol{\omega}=\left(\alpha, r, c, \pi^{M}, \pi^{D}\right)\right.$ such that $\left.0<\alpha<1,0<r<1, c>0, \pi^{M}>\pi^{D} \geq 0\right\}$.

\subsection{Research Histories, Equilibrium, and Payoffs}

Research histories To represent the progress made by the firms, we define a set of research histories. ${ }^{13}$ We use the notation $\mathbf{h}=\left(h_{1}, h_{2}\right)$, where $h_{i}$ stands for the number of steps that firm $i$ has completed. When firm $i$ completes a research step, $h_{i}$ increases by one. From a dynamic perspective, what matters is whether one research history precedes another. The research histories are partially ordered so that $\mathbf{h}$ is earlier than $\mathbf{h}^{\prime}$ if and only if $h_{i} \leq h_{i}^{\prime}$ for $i=1,2$, with strict inequality for at least one firm. In the following analysis, we refer to research histories where $h_{1}=h_{2}$ as symmetric histories and to those where $h_{1} \neq h_{2}$ as asymmetric histories.

If a firm has dropped out of the game, we use $X$ to denote this in the research history. The set of research histories is

$$
H=\left\{\left(\left(h_{1}, h_{2}\right),\left(h_{1}, X\right),\left(X, h_{2}\right) \text { for } h_{i}=1, \ldots N \text { and } i=1,2\right\}\right.
$$

Markov strategies and equilibrium We will restrict attention to strategies that depend only on the research histories in $H$. At each history, the set of available actions for firm $i$ is as follows. At symmetric histories $(h, h)$ with $h<N$ and for the histories $(h, X)$ or $(X, h)$ with $h<N$, active firms simultaneously decide whether or not to invest in the next step of research. An inactive firm is out of the game and so chooses no action. At the histories $(N, N)$, $(N, X)$ and $(X, N)$, active firms earn monopoly or duopoly profits in the product market. At

\footnotetext{
${ }^{11}$ The magnitudes of $\pi^{D}, \pi^{J}$ and $\pi^{M}$ do not depend on the decisions taken during the research phase.

${ }^{12}$ Singh and Vives (1984) show how these demand functions derive from particular consumer preferences. The Hotelling model provides another example of a differentiated duopoly.

${ }^{13} \mathrm{~A}$ research history is not a full history of the game, but rather a state variable that captures the payoff relevant history of the game.
} 
$(N, N)$, the firms earn duopoly profits. At $(N, X)$ and $(X, N)$, the active firm earns monopoly profits. At asymmetric histories $\left(h_{1}, h_{2}\right)$ where $h_{1} \neq h_{2}$, the firms move in sequence. First, the leading firm makes a take-it-or-leave-it offer to the lagging firm. Next, the lagging firm chooses whether to accept the offer. If the lagging firm accepts, the history transitions to either $\left(h_{1}+1, h_{2}\right)$ or $\left(h_{1}, h_{2}+1\right)$ depending on which firm is the leader. If the lagging firm rejects the offer, then if $h_{i}<N$, firm $i$ decides whether or not to invest in the next step of research. If both firms are choosing whether to invest, they do so simultaneously. If $h_{i}=N$, firm $i$ earns monopoly profits in the product market.

A pure Markov strategy is a function on $H$ that specifies an action for firm $i$ at each history. A pure Markov perfect equilibrium (MPE) is a subgame perfect Nash equilibrium in pure Markov strategies.

Payoffs The payoffs of each firm are functions of the current history and the equilibrium strategies. The equilibrium value functions $V_{i}(\mathbf{h})$ for $i=1,2$ are given by a Bellman equation. For histories such that the firms do not share in equilibrium, the Bellman equation for firm 1 is

$$
\begin{aligned}
V_{1}\left(h_{1}, h_{2}\right) & =\int_{0}^{\infty} e^{-(2 \alpha+r) t}\left(\alpha V_{1}\left(h_{1}+1, h_{2}\right)+\alpha V_{1}\left(h_{1}, h_{2}+1\right)-c\right) d t \text { if } h_{1}<N \text { and } h_{2}<N \\
V_{1}\left(N, h_{2}\right) & =\int_{0}^{\infty} e^{-(\alpha+r) t}\left(\pi^{M}+\alpha V_{1}\left(N, h_{2}+1\right)\right) d t \text { if } h_{2}<N \\
V_{1}\left(h_{1}, N\right) & =\int_{0}^{\infty} e^{-(\alpha+r) t}\left(\alpha V_{1}\left(h_{1}+1, N\right)-c\right) d t \text { if } h_{1}<N \\
V_{1}\left(h_{1}, X\right) & =\int_{0}^{\infty} e^{-(\alpha+r) t}\left(\alpha V_{1}\left(h_{1}+1, X\right)-c\right) d t \text { if } h_{1}<N \\
V_{1}(N, N) & =\int_{0}^{\infty} e^{-r t} \pi^{D} d t=\widetilde{\pi}^{D} \\
V_{1}(N, X) & =\int_{0}^{\infty} e^{-r t} \pi^{M} d t=\widetilde{\pi}^{M} \\
V_{1}\left(X, h_{2}\right) & =V_{1}(X, X)=0
\end{aligned}
$$

We use $V_{J}=V_{1}+V_{2}$ to refer to the joint payoffs of the firms.

Licensing fees If the firms share at an asymmetric history $\left(h_{1}, h_{2}\right)$ in equilibrium, the lagging firm pays the leading firm an licensing fee $F\left(h_{1}, h_{2}\right)$. The Bellman equation for firm 1 


$$
\begin{aligned}
& V_{1}\left(h_{1}, h_{2}\right)=F\left(h_{1}, h_{2}\right)+V_{1}\left(h_{1}, h_{2}+1\right) \text { if } h_{1}>h_{2} \\
& V_{1}\left(h_{1}, h_{2}\right)=V_{1}\left(h_{1}+1, h_{2}\right)-F\left(h_{1}, h_{2}\right) \text { if } h_{1}<h_{2} .
\end{aligned}
$$

The Bellman equation $V_{2}$ for firm 2 is defined similarly.

The leading firm makes a take-it-or-leave-it offer to the lagging firm. Because the leading firm has all the bargaining power, it offers an equilibrium licensing fee that leaves the lagging firm just indifferent between accepting and rejecting. Assuming firm 2 is the lagging firm, the licensing fee is equal to

$$
F\left(h_{1}, h_{2}\right)=V_{2}\left(h_{1}, h_{2}+1\right)-V_{2}\left(h_{1}, h_{2} ; N S\right)
$$

where $V_{2}\left(h_{1}, h_{2} ; N S\right)$ denotes the equilibrium value function conditional on the firms deciding not to share at $\left(h_{1}, h_{2}\right)$. To derive $V_{i}\left(h_{1}, h_{2} ; N S\right)$, we assume the firms do not share at $\left(h_{1}, h_{2}\right)$ and follow the equilibrium thereafter.

\subsection{Joint Profit Maximization}

As a benchmark, we briefly consider what the firms would do if they could make all of their decisions (investment, sharing and production) jointly. In the product market, it is optimal for the firms to cooperate and earn flow profits of $\pi^{J}$. Since $\pi^{J} \geq \pi^{M}$, this is the best they can do. During the research process, it is always optimal for the firms to share research successes as soon as one of them is ahead of the other. If one firm has successfully completed a step, investing to duplicate the research is purely wasteful. Since the firms make the production decision jointly, there is no reason for them to incur this extra cost.

Since costs are incurred upfront before the flow of profits begin, the incentive to invest is weakest at the beginning of the game and grows over time as the firms complete more steps of research. The expected joint payoffs at any point in time are increasing in $\alpha$ and $\pi^{J}$ and decreasing in $r$ and $c$. The firms invest provided the expected payoffs are positive. In the Poisson discovery process with identical firms, if it is optimal for one firm to invest in a step, then it is optimal for both to invest even if the firms could agree to have just one of them to invest. This speeds up the time to innovation, and the benefits of the time savings outweigh 
the costs of running simultaneous facilities. ${ }^{14}$

\section{Sharing Dynamics}

We are interested in determining the impact of competition on cooperation. Given our dynamic framework, we explore how the incentives to share change over time for rivalrous firms. In this section, we introduce a monotonicity property to formalize the idea of dynamic sharing incentives which decrease over time.

Because each of the research steps in our model is identical from a technology standpoint, a conclusion that sharing incentives must change over time is not obvious. Certainly, if one firm is ahead of the other, this may impact the firm's individual choices. However, if we consider the histories $\left(h^{\prime}+1, h^{\prime}\right)$ and $(h+1, h)$ with $h^{\prime}<h$, it is not obvious that the sharing incentives should be any different. In both cases, the leader is one step ahead of the lagging firm. Sharing is socially efficient in both cases. The history $\left(h^{\prime}+1, h^{\prime}\right)$ is, however, earlier than the history $(h+1, h)$. At the earlier history, there is more uncertainty to be resolved before the firms enter the product market and there is a longer future of strategic interaction. We want to consider how these differences affect the firms' decisions.

The number of steps that the lagging firm is behind is a factor in the firms' sharing decisions. We control for this, however, by comparing histories such that the lagging firm is a fixed number of steps behind the leading firm. We compare sharing incentives at all histories $(h+g, h)$ where $g>0$ is a fixed gap between the leading firm and the lagging firm. The size of the gap can be as small as 1 or as large as $N-1$.

Because the sharing decision is made jointly, the firms share whenever it raises their joint profits. At $(h+g, h)$, sharing changes the history to $(h+g, h+1)$. The following equilibrium sharing condition is central to our analysis:

$$
V_{J}(h+g, h+1)>V_{J}(h+g, h ; N S),
$$

where $V_{J}=V_{1}+V_{2}$ is the joint value function.

\footnotetext{
${ }^{14}$ Indeed, if there were any number of identical research facilities, then it would be optimal for all of them to conduct research simultaneously until one of the facilities achieves a success. This result does not hold if the firms are sufficiently asymmetric in their research capabilities.
} 
A sharing pattern is an ordered sequence of sharing decisions covering all histories with the same gap. For example, when $N=2$, the sharing pattern for the case when the leader is one step ahead of the lagging firm specifies sharing decisions at $(1,0)$ and $(2,1)$. For $N=2$, there is only one sharing pattern, where $g=1$. For larger $N$, there is a sharing pattern for each gap $g=1, \ldots, N-1$. The next definition states a formal monotonicity property for the general $N$-step model. We define the property for histories such that firm 1 is the leader. Because the equilibria in our game are symmetric, when the property holds, it also holds for histories such that firm 2 is the leader.

Definition 1 An equilibrium satisfies the monotonicity property if whenever the firms share at the history $(h+g, h)$, then they also share at the earlier history $\left(h^{\prime}+g, h^{\prime}\right)$ where $h^{\prime}<h$. Here $h$ and $h^{\prime}$ range from 0 to $N-g$ and $g=1, \ldots, N-1$.

A sharing pattern is monotonic if once firms stop sharing, they never share again. Hence, when the property holds, sharing incentives may be said to decline over time as the firms approach the end of the game. For $N=2$, there are four possible sharing patterns: $(\mathrm{S}, \mathrm{S})$, (S,NS), (NS,NS), and (NS,S). All patterns except (NS,S) are monotonic.

\section{Two-step Research Process}

We are now in a position to analyze the model when $N=2$. Our central question is whether the firms' incentives to share decline over time as they approach the product market. That is, we ask whether the equilibrium sharing pattern is monotonic. Because the project has two steps, there are six histories at which one firm has more knowledge than the other. These are the histories $(1,0),(0,1),(2,0),(0,2),(2,1)$ and $(1,2)$.

There are two principle motivations for firms to decide against sharing. First, if the lagging firm continues to research, it will take longer to finish the project allowing a longer expected period of monopoly profits for the leading firm. Second, if the lagging firm exits the game, the leader can expect to earn monopoly profits forever upon finishing. It turns out that these two motivations can lead to different dynamics over time. We consider environments with and without exit separately. 


\subsection{Dynamics of Sharing When Firms do not Exit the Game}

In this section, we prove our main monotonicity result that the firms' incentives to share decline over time. The incentive to share depends on the joint profits of the two firms, not their individual profits. We discuss the dynamics of the individual profits and the licensing fees that the lagging firm pays to the leading firm at the end of the section after presenting the monotonicity result.

We start by distinguishing parameter regions with and without exit.

Definition 2 Region A consists of those parameter values such that in every Markov perfect equilibrium of the game, firms do not exit at any history either on the equilibrium path or off the equilibrium path. Region $B$ consists of all other parameter values.

Region A is given as follows:

Lemma 1 Region A consists of all parameters such that $\pi^{D} \geq c \frac{r}{\alpha}\left(2+\frac{r}{\alpha}\right)$.

The proof of Lemma 1 focuses on a firm that is as far behind the leader as possible when the leader has not shared its research. Because the lagging firm does not have any bargaining power, its payoff if there is no sharing at $(2,0)$ is the payoff it would get by conducting the two steps of research on its own and then producing in the output market as a duopolist. Intuitively, this is the worst possible position for a firm. We show that the lagging firm stays in at these histories if and only if the inequality $\pi^{D} \geq c \frac{r}{\alpha}\left(2+\frac{r}{\alpha}\right)$ holds.

This inequality implies that environments without exit arise when competition in the product market is relatively soft and the costs of research (time and money) are not prohibitive. Otherwise, if the product market competition will be intense, then we are in Region B where a lagging firm drops out at one or more histories.

Because the firms never exit in Region A, solving the game for its equilibria reduces to determining the sharing decisions of the firms. The next proposition records our main monotonicity result.

Proposition 1 In Region A, every MPE sharing pattern is monotonic. 
The proposition is proved in the appendix where we solve for the equilibria in Region A. There is a unique MPE except on boundaries between the subregions of Region A where some equilibrium action changes. The proposition implies that whenever the firms share at the history $(2,1)$, they also share at the earlier history $(1,0)$. Therefore, we would expect to see only the monotonic sharing patterns: (S,S), (S,NS) and (NS,NS). The sharing pattern (NS,S) never arises in Region A. Hence, if sharing breaks down, it breaks down as the firms approach the time when they will be competitors.

We explain the reasons behind Proposition 1 by discussing the sharing conditions at $(2,1)$ and $(1,0)$. At both histories, the firms share if and only if doing so increases their joint continuation profits. The benefit of sharing is the savings of duplicated R\&D costs for one step of research. Sharing also has the benefit of bringing the product market profits forward. However, those product market profits may be reduced as a result of sharing since sharing decreases the leader's ability to earn monopoly profits. The sharing decision depends upon the balance of these costs and benefits.

Formally, firms share at $(2,1)$ if $V_{J}(2,2)>V_{J}(2,1 ; N S)$. If the firms share, they compete as duopolists in the product market and earn joint flow profits of $2 \pi^{D}$. Their continuation profits are $V_{J}(2,2)=2 \widetilde{\pi}^{D}$. If the firms do not share, the leading firm earns a flow profit of $\pi^{M}$ and the lagging firm invests $c$ until the lagging firm finishes. Their joint continuation profits are $V_{J}(2,1 ; N S)=\int_{0}^{\infty} e^{-(\alpha+r) t}\left(\pi^{M}-c+\alpha V_{J}(2,2)\right) d t$. The sharing condition simplifies to

$$
2 \pi^{D}-\left(\pi^{M}-c\right)>0 .
$$

At the earlier history $(1,0)$, the sharing condition is $V_{J}(1,1)>V_{J}(1,0 ; N S)$. The joint payoffs at $(1,1)$ and $(1,0 ; N S)$ depend on future sharing decisions at $(2,1)$ and $(2,0)$. Hence, we consider these decisions first.

First, consider the case when condition (3) fails, ${ }^{15}$ so the firms do not share at $(2,1)$. As shown in the appendix, the sharing condition at $(2,0)$ is the same as the sharing condition at $(2,1)$. Thus, the firms do not share at $(2,0)$ either. To understand why, note that sharing at $(2,0)$ changes the history to $(2,1)$ and allows the lagging firm to reach the product market sooner. When this happens, the flow profits $\left(\pi^{M}-c\right)$ are replaced by the flow profits $2 \pi^{D}$ for

\footnotetext{
${ }^{15}$ By failing, we mean that the inequality in condition (3) is reversed. The special case that the condition holds with equality is considered in the appendix and is discussed further below.
} 
a net loss of $2 \pi^{D}-\left(\pi^{M}-c\right)$. To avoid this loss, the firms do not share at $(2,0)$.

Now, consider the sharing condition at $(1,0)$. At $(1,0)$, there is a new benefit of sharing that did not exist at $(2,1)$. The lagging firm now has a chance of finishing first. If the firms knew that firm 2 would finish first, they would want to share at $(1,0)$ so as to realize monopoly profits sooner. In contrast, if the firms knew that firm 1 would finish first, then they would not want to share at $(1,0)$ because this shortens the duration of monopoly profits. We can re-write the sharing condition (21) in the appendix in the following way:

$$
\beta\left(\pi^{M}+c\right)+(1-\beta)\left(2 \pi^{D}-\left(\pi^{M}-c\right)\right)>0,
$$

where $\beta=\frac{(\alpha+r)^{2}}{(2 \alpha+r)^{2}}$. The second term in (4) is the net loss in joint flow profits when the leading firm finishes first. This is the same as condition (3) and is negative. The first term in (4) is the increase in joint flow profits when the lagging firm finishes first. Here, the firms jointly benefit from replacing the lagging firm's R\&D costs $-c$ with monopoly profits $\pi^{M}$. The net benefit, $\pi^{M}+c$, is positive. The $\beta$ and $(1-\beta)$ can be interpreted as weighted probabilities, where flow profits that arrive earlier in time have greater weight. There is a weighted probability $\beta$ that the lagging firm finishes first and a weighted probability $(1-\beta)$ that the leading firm finishes first. Since $\beta>0$, condition (4) is easier to satisfy than (3) so that the monotonicity result holds. At $(2,1), \beta=0$ because the leading firm was already done.

When condition (4) holds, there is a unique MPE with the sharing pattern (S,NS). When it fails, there is a unique MPE with the sharing pattern (NS,NS). When the condition holds with equality, there are two MPEs, one for each sharing pattern.

Next, consider the case when condition (3) holds, so the firms share at $(2,1)$. As shown in the appendix, the sharing condition at $(2,0)$ is again the same as the sharing condition at $(2,1)$ and is given by condition (3). Thus, the firms share at $(2,0)$ also.

As shown in the appendix, the sharing condition at $(1,0)$ simplifies to

$$
\pi^{D}+c>0
$$

which holds trivially and implies that the equilibrium sharing pattern is (S,S). Since the firms share at both $(2,1)$ and $(2,0)$, neither firm can ever earn monopoly profits and, thus, there is no cost to sharing at $(1,0)$. Sharing merely reduces the expected time to market and expected $\mathrm{R} \& \mathrm{D}$ costs by enabling the lagging firm to finish sooner. The sharing condition captures the 
change in joint flow profits when this happens. When the lagging firm reaches the history $(1,2)$, the firms share so that both firms enter the product market. As shown in (5), the joint flow profits increase from $-2 c$ to $2 \pi^{D}$ for a net benefit of $2\left(\pi^{D}+c\right)>0$. Sharing at $(1,0)$ creates this benefit by enabling the firms to reach the history $(1,2)$ sooner and with a higher probability. Clearly, condition (5) is easier to satisfy than condition (3) in so far as it holds for more parameter values.

In summary, there are two explanations for why sharing patterns are monotonic. The first explanation is that if the firms do not share at $(2,1)$, sharing at $(1,0)$ may still be beneficial because it enables the lagging firm to finish first and earn monopoly profits sooner. The second explanation is that future sharing at $(2,1)$ and $(2,0)$ eliminates the ability of either firm to earn monopoly profits. This eliminates the cost of sharing earlier in the game and explains why (5) holds trivially. It is interesting to note that the dynamics described above continue to hold when research costs $c$ are zero. In particular, savings of duplicated R\&D costs are not the only reason the firms find it optimal to share. Firms are also motivated to share so that they can reduce the time needed for one or both to reach the product market.

\subsubsection{Comparative Statics}

We next consider how the extent of sharing is affected by changes in parameters to better understand the dynamic motivations for sharing. From Proposition 1, we can describe a monotonic sharing pattern by the number of histories in which the firms choose to share. For example, (NS,NS) implies that there are no histories with sharing while (S,NS) implies that there is one and $(\mathrm{S}, \mathrm{S})$ implies that there are two histories with sharing.

Corollary 1 Consider any $\boldsymbol{\omega}=\left(\alpha, r, c, \pi^{M}, \pi^{D}\right)$ and $\boldsymbol{\omega}^{\prime}=\left(\alpha^{\prime}, r^{\prime}, c^{\prime}, \pi^{M^{\prime}}, \pi^{D^{\prime}}\right)$ in Region A such that $\alpha \leq \alpha^{\prime}, r \geq r^{\prime}, c \geq c^{\prime}, \pi^{M} \leq \pi^{M^{\prime}}$ and $\pi^{D} \geq \pi^{D^{\prime}}$. Select a MPE at $\boldsymbol{\omega}$ and $\boldsymbol{\omega}^{\prime}$ and consider the associated sharing patterns. There are weakly more histories with sharing at $\boldsymbol{\omega}$ than at $\boldsymbol{\omega}^{\prime}$.

The Corollary is proved by an examination of the sharing conditions given in (3), (4), and (5). Intuitively, it is clear that an increase in duopoly profits, $\pi^{D}$, or in the research cost, $c$, increases the attractiveness of sharing. Both enter with a positive sign in each sharing condition. The effects of the other parameters are less obvious. 
First, consider the comparative statics result for monopoly profits, $\pi^{M}$. Condition (3) implies that an increase in $\pi^{M}$ decreases the incentive to share at $(2,1)$. This is because sharing erodes the monopoly profits of the leading firm. At the earlier history $(1,0)$, however, the role of $\pi^{M}$ is more complex. As seen in (5), if the firms share at $(2,1)$, then an increase in $\pi^{M}$ has no effect on the sharing decision at $(1,0)$. This is because the firms never earn monopoly profits due to future sharing. If the firms do not share at $(2,1)$, an increase in $\pi^{M}$ can either increase or decrease the incentive to share at $(1,0)$. As shown in (4), if $\beta<\frac{1}{2}$, the sharing condition at $(1,0)$ gives more weight to the erosion of monopoly profits for the leading firm, $\left(2 \pi^{D}-\left(\pi^{M}-c\right)\right)$. This term is decreasing in $\pi^{M}$. If $\beta>\frac{1}{2}$, the sharing condition gives more weight to the benefit of sharing for the lagging firm, $\pi^{M}+c$, which is increasing in $\pi^{M}$. Corollary 1 states that an increase in $\pi^{M}$ always results in fewer histories with sharing. When $\beta<\frac{1}{2}$, this is clearly true. When $\beta>\frac{1}{2}$, the result holds weakly because, even though the underlying effect of an increase in $\pi^{M}$ is to increase the incentives to share, the firms share at $(1,0)$ regardless of $\pi^{M}$. To see this, note that the lowest value of $\pi^{M}$ in our parameter space is $\pi^{M}=\pi^{D}$. At this value of $\pi^{M}$, if $\beta>\frac{1}{2}$, condition (4) holds. For larger $\pi^{M}$, thus, the condition also holds.

Next, consider the comparative statics results for $r$ and $\alpha$. Of the three sharing conditions above, the only one affected by $r$ and $\alpha$ is (4). This is the condition for sharing at $(1,0)$ if the firms do not share at $(2,1) .{ }^{16}$ The parameters $r$ and $\alpha$ enter $(4)$ through the parameter $\beta$ which is increasing in $\frac{r}{\alpha}$. The ratio $\frac{r}{\alpha}$ can be interpreted as a discount factor. The underlying interest rate $r$ is adjusted by the effectiveness $\alpha$ of the research technology. As $\frac{r}{\alpha}$ increases, the firms become more impatient and so place more weight on reducing the delay until at least one of them enters the product market and less weight on extending the duration of monopoly profits. This makes sharing more appealing. In fact, for $\beta>\frac{1}{2}$, sharing at $(1,0)$ is always optimal, even for arbitrarily large values of $\pi^{M}$.

Figure 1 lists the sharing patterns for different regions. The parameters $\alpha, r$, and $c$ are fixed, but $\pi^{D}$ and $\pi^{M}$ are allowed to vary. The right hand side of the diagram, where $\pi^{D} \geq c \frac{r}{\alpha}\left(2+\frac{r}{\alpha}\right)$, depicts the equilibrium outcomes in Region A. Consider how the sharing pattern changes as

\footnotetext{
${ }^{16}$ The sharing condition $(3)$ at $(2,1)$ is not affected by $\frac{r}{\alpha}$ because the cost and benefit of sharing are incurred at the same time in the flow of profits. Similarly, in the sharing condition $(5)$ at $(1,0)$, when the firms share at $(2,1), \frac{r}{\alpha}$ does not affect the flow benefit of sharing given by $2\left(\pi^{D}+c\right)$.
} 


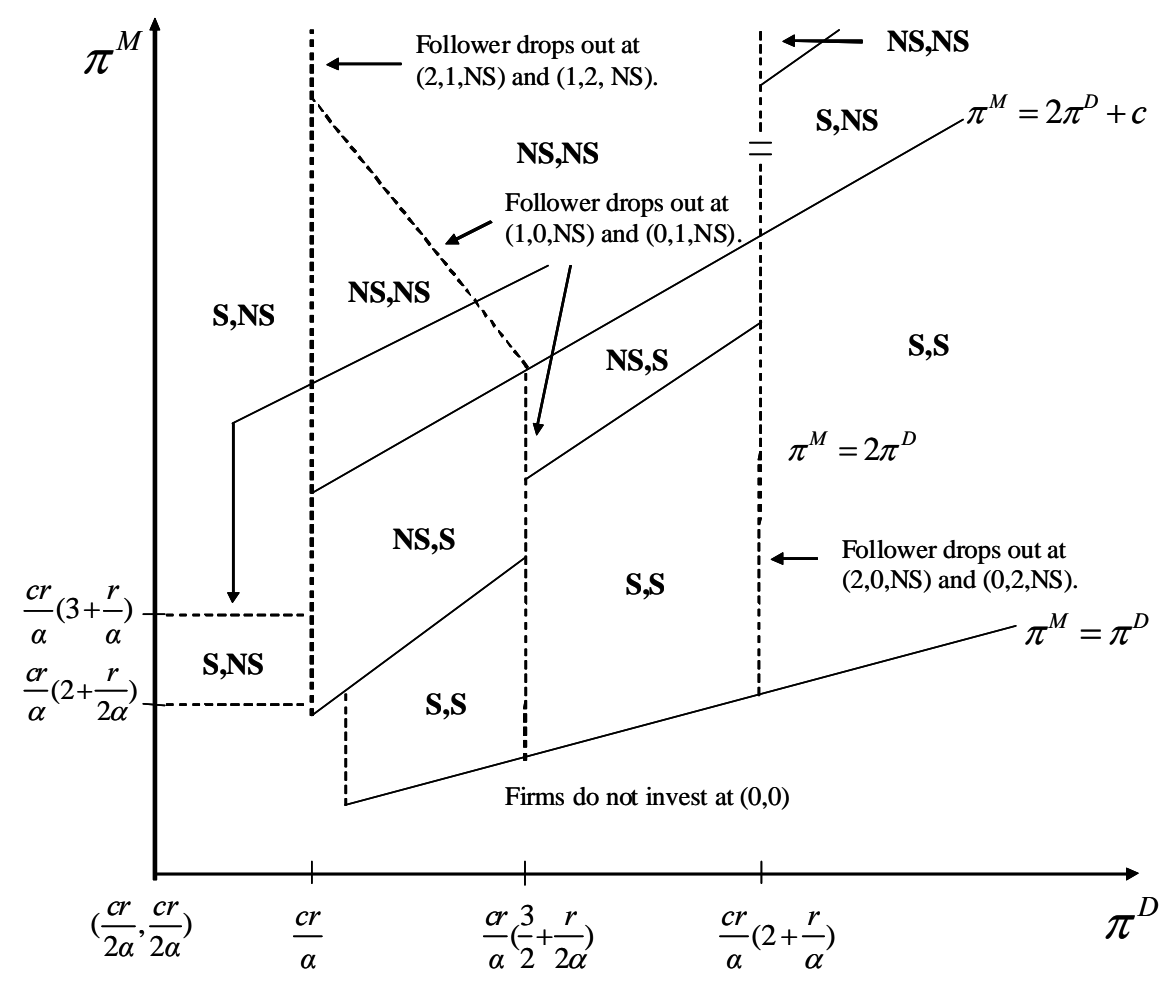

Figure 1: Equilibrium Outcomes for $\alpha=.5, r=.2$ and $c=.5$

$\pi^{M}$ increases for a given value of $\pi^{D}$. The values of $r$ and $\alpha$ yield $\beta<\frac{1}{2}$ so that an increase in $\pi^{M}$ increases the incentive to choose NS at all the histories. For small values of $\pi^{M}$, the sharing pattern is $(\mathrm{S}, \mathrm{S})$. As monopoly profits increase, sharing breaks down at the history $(2,1)$ and the sharing pattern is (S,NS). As monopoly profits increase further, sharing eventually breaks down at the earlier history $(1,0)$ as well, so the sharing pattern is (NS,NS). Hence, as $\pi^{M}$ increases, sharing breaks down, but it breaks down at later histories first.

\subsubsection{Licensing Fees}

To finish, we briefly discuss individual payoffs and licensing fees. Since sharing decisions are made jointly, they do not depend on this analysis. However, it is still interesting to consider the dynamics of the licensing fees. In light of the monotonicity we have observed in the sharing incentives, a natural question that arises is whether the licensing fees display a similar type of dynamics. We find that this is not necessarily the case. Although the joint incentives to share decline over time, the licensing fees paid by the lagging firm may increase or decrease 
over time depending on the magnitude of $\frac{r}{\alpha}$.

Recall that whenever the firms share, the leading firm makes a take-it-or-leave-it offer to the lagging firm. Since the leading firm has all the bargaining power, it offers a licensing fee that leaves the lagging firm just indifferent between accepting and rejecting. In section $\mathrm{C}$ of the appendix, we analyze an MPE in which the firms share at all histories. We find that both firms have a higher payoff at $(2,1)$ than at $(1,0)$. Essentially, this is because costs are invested upfront while profits are earned later and are discounted. Hence, as the game progresses, individual payoffs rise. For this reason, if $\frac{r}{\alpha}$ is sufficiently high, the licensing fees also increase over time. This is in contrast with the sharing incentives which decrease over time.

For sufficiently small values of $\frac{r}{\alpha}$, the dynamics of the sharing incentives do, however, determine the dynamics of the licensing fees. The benefit from sharing to the lagging firm (as opposed to the joint benefit) is higher at $(1,0)$ than at $(2,1)$ because at $(1,0)$, sharing helps the lagging firm to finish first and earn a licensing fee at $(1,2)$. This effect dominates for sufficiently small values of $\frac{r}{\alpha}$ and $F(1,0)>F(2,1)$. This is because when $\frac{r}{\alpha}$ is small, discounting does not reduce the payoffs early in the game by much. Since discounting plays a smaller role than the sharing dynamics in the determination of the licensing fees, the licensing fees display a monotonic pattern consistent with the pattern of the sharing incentives. Hence, whether licensing fees have the same dynamics as the sharing incentives depends on how impatient the firms are to reach the product market.

\subsection{Dynamics of Sharing When Firms Exit the Game}

We next consider region B. In this region, a lagging firm may exit the game if the leader does not share at some history. Competition in the product market is sufficiently intense or research costs are sufficiently high so that firms may exit when they fall behind. This introduces an important strategic motive for a leading firm to refuse to share. Our question is whether, in light of this, the pattern of sharing continues to satisfy the monotonicity property. We find that this is not the case. A lagging firm may be more likely to drop out earlier in the game, when it has more research left to complete. Given this, a leading firm may be less likely to share earlier in the game.

Proposition 2 In Region B, for an open set of parameters, there is a MPE such that the 
firms share at $(2,1)$ but not at $(1,0)$, where both histories arise on the equilibrium path.

The proposition is proved in the appendix. For a region of parameter values, we demonstrate a unique equilibrium in which a non-monotonic sharing pattern arises on the equilibrium path. The firms share at $(2,1)$, but they do not share at $(1,0)$. This is because by not sharing at $(1,0)$, the firms can reach the history $(2,0)$. At $(2,0)$, the firms do not share and the lagging firm drops out. The leading firm then earns monopoly profits forever. In the equilibrium, $(2,0 ; N S)$ is the only history at which the lagging firm drops out. At $(2,1 ; N S)$ and $(1,0 ; N S)$, the lagging firm stays in the race. Thus, the firms have a strong incentive to forego sharing at $(1,0)$ in order to reach $(2,0)$. A non-monotonic sharing pattern arises on the equilibrium path when, after choosing not to share at $(1,0)$, the firms next reach the history $(1,1)$ rather than $(2,0)$. The game then proceeds to $(2,1)$ or $(1,2)$, at which point the firms share step 2 .

In a companion appendix, we solve for all of the equilibria of the model. ${ }^{17}$ There, we demonstrate another equilibrium where the monotonicity property fails. In that equilibrium, the firms choose not to share at $(1,0)$ because then the lagging firm immediately drops out. Because of this, the firms never reach the history $(2,1)$ on the equilibrium path. They do share at $(2,1)$ off the equilibrium path however, so technically the monotonicity property fails.

Figure 1 depicts the equilibrium outcomes in the case when we see non-monotonic sharing patterns both on and off the equilibrium path. ${ }^{18}$ The two regions with the non-monotonic sharing pattern (NS,S) are separated by the vertical line $\pi^{D}=c \frac{r}{\alpha}\left(\frac{3}{2}+\frac{r}{2 \alpha}\right)$. In the region to the left of this line, the lagging firm drops out at the history $(1,0)$ if the firms do not share. Thus, an observer of the game would not observe a non-monotonicity. In the region to the right of the line, the lagging firm stays in the game at the history $(1,0)$ if the firms do not share. Because of this, an observer of the game would observe a non-monotonicity.

Although we have demonstrated how the possibility of drop out may result in no sharing, it is important to note that it may also increase the incentives to share. That is, the firms sometimes share at $(1,0)$ in Region B to keep the lagging firm in the race. This happens on the left hand side of Figure 1, below the horizontal line $\pi^{M}=c \frac{r}{\alpha}\left(3+\frac{r}{\alpha}\right)$, where the sharing pattern

\footnotetext{
${ }^{17}$ The appendix is available at http://www.economics.unimelb.edu.au/nerkal/homepage/index.htm.

${ }^{18}$ There are multiple equilibria at $(0,0)$ in some of the regions. Both firms can be in or both firms can be out at $(0,0)$. In the diagram, we selected the equilibrium such that both firms invest at $(0,0)$. In the companion appendix, some of the regions shown above are further divided because we specify the sharing decision at $(2,0)$ also.
} 
is $(\mathrm{S}, \mathrm{NS})$. The firms share at $(1,0)$ despite the fact that the lagging firm would immediately drop out otherwise. Sharing enhances joint profits because the lagging firm may finish the race faster than the leading firm, so that monopoly profits are earned sooner. In this region, there are also multiple equilibria at $(0,0)$, one where both firms invest and another one where neither firms invests. When both firms invest, the firms benefit from each other's presence because of future sharing at $(1,0)$ and $(0,1)$. But for this sharing, neither would have wanted to invest at $(0,0)$.

The left hand side of Figure 1 also shows that if the firms play a winner-take-all game, they may have incentives to share early in the game. We interpret the game as a winner-take-all game when the firms do not share at $(2,1)$ and the lagging firm then drops out. As can be seen on the left hand side of Figure 1, we would always expect the firms to share the first research step in this case. This is because the firms will never compete as duopolists and they can maximize joint profits by reaching the product market as quickly as possible. Sharing allows them to achieve exactly this. It is important to point out that it is not the level of spillovers which explains the sharing between the firms. Rather, it is the dynamics of competition.

The results in sections 4.1 and 4.2 relate to a fundamental question in the economics of $R \& D$ on how competition affects the incentives for cooperation in $R \& D$. They reveal that the dynamic impact of competition on cooperation is complex. The sharing incentives may either increase or decrease throughout a research process. In less competitive industries (where, as in Region A, the lagging firm pursues duopoly profits rather than exiting), the firms will have decreasing incentives to share. In more competitive industries (where, as in Region B, the lagging firm exits at some histories), the firms may have either decreasing or increasing incentives to share. As discussed in the conclusion, these results have implications for government policy towards sharing arrangements.

\section{$5 \quad N$-step Research Process}

In this section, we discuss some results obtained in a model with $N$ research steps of equal difficulty as robustness check. We focus on the main question of whether the sharing patterns in Region A continue to be monotonic. We first consider the case when $N=3$. Lemma 1 extends in a straightforward way and Region $\mathrm{A}$ is the set of parameters such that the lagging firm stays 
in the game at the history $(3,0 ; N S)$. Specifically, it is defined by $\pi^{D} \geq c \frac{r}{\alpha}\left(3+3 \frac{r}{\alpha}+\frac{r^{2}}{\alpha^{2}}\right)$.

The next proposition states how the result in Proposition 1 extends to a model with three research steps.

Proposition 3 Suppose $N=3$. In Region A, every MPE sharing pattern is monotonic.

To prove the proposition, we derive the equilibria as we did for the case of $N=2$. These derivations are available on request. With a three-step research process, we can compare the sharing incentives at the histories where the leader is one step ahead of the lagging firm (i.e., at $(1,0),(2,1)$, and $(3,2))$ as well as at the histories where the leader is two steps ahead of the lagging firm (i.e., at $(2,0)$ and $(3,1))$. Proposition 3 implies that both types of sharing patterns are monotonic. For the histories $(1,0),(2,1)$, and $(3,2)$, there exist parameter values where the equilibrium sharing decisions are (S,S,S), (S,S,NS), (S,NS,NS) or (NS,NS,NS). For the histories $(2,0)$ and $(3,1)$, there exist parameter values where the equilibrium sharing decisions are $(\mathrm{S}, \mathrm{S})$, $(\mathrm{S}, \mathrm{NS})$ or $(\mathrm{NS}, \mathrm{NS}) \cdot{ }^{19}$

The sharing condition at all histories such that one firm is finished is again given by (3). When this condition holds, the firms share at the histories $(3,0),(3,1)$ and $(3,2)$. This removes the possibility of monopoly profits, so the firms share at all earlier histories also. The sharing condition at all earlier histories is given by (5). When (3) fails, the firms do not share at $(3,0),(3,1)$, or $(3,2)$. At all earlier histories and in every equilibrium, the equilibrium sharing condition has the form

$$
\beta\left(\pi^{M}+c\right)+(1-\beta)\left(2 \pi^{D}-\left(\pi^{M}-c\right)\right)>0,
$$

where $\beta \in(0,1)$ depends on the history and the future sharing decisions. In each equilibrium, when we compare the sharing conditions at two histories with the same gap, we find that the value of $\beta$ is higher at the earlier history. This gives us the monotonicity result.

The main intuition for this monotonicity result is the following. While the firms jointly decide whether to share, the basic trade-off they face is between maintaining the leader's lead

\footnotetext{
${ }^{19}$ In Region A, when (3) holds, the unique MPE sharing pattern is $(\mathrm{S}, \mathrm{S}, \mathrm{S})$ if the gap between the firms is one $(g=1)$ and $(\mathrm{S}, \mathrm{S})$ if $g=2$. When (3) fails, for small $\frac{r}{\alpha}$, the unique MPE sharing pattern is (NS,NS,NS) for $g=1$ and (NS,NS) for $g=2$. As $\frac{r}{\alpha}$ increases, the unique MPE sharing pattern becomes (S,NS,NS) for $g=1$ and (NS,NS) for $g=2$, then (S,S,NS) for $g=1$ and (NS,NS) for $g=2$, and then (S,S,NS) for $g=1$ and (S,NS) for $g=2$.
} 
so that he can earn monopoly profits for longer period of time when he finishes first and enabling the lagging firm to finish first at an earlier point in time. Note that at symmetric histories, each firm has an ex ante $50 \%$ chance of finishing first. When one firm is ahead by one step, that firm has more than a 50\% chance of finishing first. Because of this, the concern about keeping the leader's lead has a greater weight in the decision than if the firms were in a symmetric position. The monotonicity result follows because as the game progresses, the weight put on this concern increases. That is, as the game progresses, a lead of a fixed number of steps gives the leading firm a greater chance of finishing first. To see this, note that at the history $(N, N-1)$, since the leader is done, his lead gives him a $100 \%$ chance of finishing first. The sharing condition in this case places no weight on the benefit of enabling the lagging firm to finish first $(\beta=0)$ because the lagging firm cannot finish first. When the game is longer, however, the fact that the leader is one step ahead does not give him a $100 \%$ chance of finishing first. In fact, the longer is the game, the closer the leader's chance of finishing is to $50 \%{ }^{20}$ Hence, there is a lower and lower weight placed on the concern about keeping the leader's lead. Thus, the firms have increasing incentives to share as we go back in time.

The monotonicity result cannot be strengthened to comparisons between histories such that the leading firm is ahead by a differing number of steps. For example, we find an equilibrium such that the firms share at $(2,1)$, but do not share at the earlier history $(2,0)$. The reason is that at $(2,0)$, the leading firm is further ahead and has more to give up in terms of forgone monopoly profits.

We expect that Proposition 1 could be extended further to a model with $N$ research steps. ${ }^{21}$ However, we have not proved this because the equilibrium calculations become too cumbersome. Instead, we analyzed a related problem that we interpret as a partial generalization of our monotonicity result. Consider any starting history $(h+1, h)$ in the $N$-step model such that the leading firm is one step ahead of the lagging firm. Assume that at all histories after $(h+1, h)$ the firms do not share and they also do not exit the game. ${ }^{22}$ Under this assump-

\footnotetext{
${ }^{20}$ Note that $\beta$ above is not literally the ex ante probability that the lagging firm finishes first. It is a normalized, weighted discount factor corresponding to changes in the flow of joint profits that occur when sharing causes the lagging firm to finish earlier and before the leading firm. When these changes occur earlier in time, they receive a higher weight.

${ }^{21}$ Note that Region A shrinks as $N$ increases because a lagging firm has a lower payoff from staying in the game at $(N, 0)$ than at $(N-1,0)$. Region $\mathrm{B}$ grows as Region A shrinks since they are complementary sets.

${ }^{22}$ We know from the analysis in section 4.1 that if the firms always share in the future, the sharing condition
} 
tion, we can derive formulas representing the firms' joint continuation payoffs and compare the continuation payoffs from sharing and not sharing at $(h+1, h)$. The sharing condition always has the form (6), so we can define $\beta(h+1, h)$. Numerical analysis reveals that $\beta(h+1, h)$ is decreasing in $h$ for $N \leq 20 .{ }^{23}$ This means that if the sharing condition holds at the history $(h+1, h)$, then it holds at all earlier histories $\left(h^{\prime}+1, h^{\prime}\right)$ where $h^{\prime}<h$. The result is different from Proposition 1 because the assumptions about the firms' behavior after $(h+1, h)$ may not be consistent with any equilibrium. ${ }^{24}$ However, the result is consistent with the intuition that the incentives to share decline over time when firms never exit.

\section{Asymmetric Firms}

So far we have assumed that the firms are symmetric in their research capabilities. This allowed us to focus on the impact of uncertainty and progress on the firms' sharing decisions. In this section, we relax the symmetry assumption by allowing the firms to have different research costs. This allows us to consider two environments that commonly arise in practice, where there is a dominant research firm and where firms have different abilities to conduct different stages of research. ${ }^{25}$ We have two results. First, we show that if one of the firms is more efficient at conducting research, sharing patterns continue to be monotonic in Region A. Second, we show that if one of the firms is more efficient at first-stage research than at second-stage research, then the monotonicity result may be violated.

Let the research costs of firm 1 and firm 2 be $c_{1}$ and $c_{2}$, respectively. To start with, we assume that firm 1 is more efficient than firm 2 so that $c_{1}<c_{2}$. Each firm has the same cost of research in both stages. Hence, there is symmetry across the different stages of research for each

holds trivially because there is no cost to sharing. We are considering the other extreme here and assume that the firms never share in the future. This allows us to focus on the intuition that the further away the firms are from the end of the research process, the more uncertainty they face and the more willing they may be to share.

${ }^{23}$ We compared the payoffs by evaluating them on a discrete grid of parameter values. The formulas appear to be sufficiently continuous that we do not expect we missed any singularities in our simulations. The computations are available on request.

${ }^{24}$ However, based on our discussion in section 1, we conjecture that such an equilibrium would exist for sufficiently small values of $\frac{r}{\alpha}$. For $\frac{r}{\alpha}$ sufficiently small, the firms do not exit the game at any history. Moreover, as $\frac{r}{\alpha}$ decreases, firms become more patient and are less concerned with reducing the delay until the lagging firm enters the product market. Since the benefit from sharing decreases, we expect there to be a unique MPE such that the firms choose NS at every history and never drop out of the game.

${ }^{25}$ In the biotechnology industry, for example, alliances often involve a firm which has developed expertise in research on a particular biotechnology and a large pharmaceutical which may be better able to bring the product through the clinical testing and regulatory approval process to the market. See Lerner and Merges (1998). 
firm, but asymmetry between the research costs of the two firms. The model is now defined for $\Omega=\left\{\left(\alpha, r, c_{1}, c_{2}, \pi^{M}, \pi^{D}\right)\right.$ such that $\left.0<\alpha<1,0<r<1, c_{2}>c_{1}>0, \pi^{M}>\pi^{D} \geq 0\right\}$. Since firm 2 is the less efficient firm, Region A is defined by $\pi^{D} \geq c_{2} \frac{r}{\alpha}\left(2+\frac{r}{\alpha}\right)$.

Because of the cost asymmetry, sharing at the history $(h+g, h)$ no longer implies sharing at the history $(h, h+g)$. In light of this, we now define a sharing pattern as an ordered sequence of sharing decisions covering all histories with the same gap and with the same firm acting as the leader. This implies, for $N=2$, there are two sharing patterns for each equilibrium, one associated with each firm being the leader. The following definition states the monotonicity property separately for each firm.

Definition 3 An equilibrium satisfies the monotonicity property for firm 1 (respectively for firm 2) if whenever the firms share at the history $(2,1)$ (respectively $(1,2)$ ), then they also share at the earlier history $(1,0)$ (respectively $(0,1)$ ).

We analyze whether both sharing patterns are monotonic in Region A, where both firms invest at every history. Consider the histories $(2,1)$ and $(1,2)$. As in the previous analysis, the cost of sharing is $\pi^{M}-2 \pi^{D}$. The sharing condition at $(2,1)$ is $c_{2}>\pi^{M}-2 \pi^{D}$ and the sharing condition at $(1,2)$ is $c_{1}>\pi^{M}-2 \pi^{D}$. Because $c_{1}<c_{2}$, the sharing condition at $(2,1)$ is easier to satisfy. This leaves us with three cases: i) The firms share at both histories, ii) the firms share at neither history, and iii) the firms share at $(2,1)$ but not at $(1,2)$.

Proceeding in the same way as we did in the symmetric case, we have the following result.

Proposition 4 Suppose that firm 1's research cost is $c_{1}$, firm 2's research cost is $c_{2}>c_{1}$, and that the firms have the same research cost in both stages of the research process. Then, in Region A, every MPE sharing pattern is monotonic.

Proposition 4, proved in the appendix, states that sharing patterns continue to be monotonic even if the firms differ in their research costs. As long as each firm's research costs do not change over time, the firms receive higher joint benefits from sharing earlier rather than later in the research process for essentially the same reasons as in the symmetric model. The scenario that is most interesting to consider is when, due to the asymmetry in their research costs, the firms share at $(2,1)$ but not at $(1,2)$. This occurs when $c_{2}>\pi^{M}-2 \pi^{D}>c_{1}$. For the sharing 
patterns where firm 1 is the leader to be monotonic, the firms must share at $(1,0)$ since they share at $(2,1)$. As shown in the appendix, this is indeed the case. Intuitively, this can be understood as follows. Because the firms share at $(2,1)$, firm 1 does not forego any future monopoly profits by sharing at $(1,0)$. On the other hand, sharing at $(1,0)$ makes it more likely that firm 2 will finish first. Sharing also eliminates duplicative research on stage 1 . Thus, there is no downside to sharing at $(1,0)$. Since the firms start to make joint flow profits of $\pi^{M}-c_{1}$ instead of $-\left(c_{1}+c_{2}\right)$, the sharing condition at $(1,0)$ is $\pi^{M}+c_{2}>0$.

Since the firms do not share at $(1,2)$, it is trivially the case that all sharing patterns with firm 2 as the leader are monotonic. The sharing condition at $(0,1)$, however, has some interest. From (33) in the appendix, it is given by

$$
\beta\left(2 \pi^{D}+c_{1}+c_{2}\right)+(1-\beta)\left(2 \pi^{D}-\pi^{M}+c_{1}\right)>0,
$$

where $\beta=\frac{(\alpha+r)^{2}}{(2 \alpha+r)^{2}}$. The first term in $(7), 2 \pi^{D}+c_{1}+c_{2}$, is positive. It arises because sharing at $(0,1)$ helps the firms reach $(2,1)$. At $(2,1)$, the firms share and joint flow profits increase from $-\left(c_{1}+c_{2}\right)$ to $2 \pi^{D}$. Sharing at $(0,1)$ thus brings about cost savings for both firms. In particular, the higher is the leader's $\operatorname{cost} c_{2}$, the greater is the incentive to share. The second term in (7) is negative because $\pi^{M}-2 \pi^{D}>c_{1}$. This is the usual loss that arises when, due to sharing, the lagging firm erodes the monopoly profits of the leading firm. In the equilibrium, the benefit in the first term dominates the loss in the second term, and the firms always share at $(0,1)$. Hence, future sharing at $(2,1)$ is sufficient to induce sharing at both of the earlier histories $(1,0)$ and $(0,1)$ even though the firms do not share at $(1,2)$.

Next, we consider a different type of asymmetry, where one of the firms is better at one stage of research than at the other stage of research. Suppose, as above, that firm 1 has a cost of $c_{1}$ in both stages, but firm 2 has a cost of $c_{2}^{1}$ in the first stage and $c_{2}^{2}$ in the second stage. The only new asymmetry we introduce is in the research costs of firm 2 . The model is now defined for $\Omega=$ $\left\{\left(\alpha, r, c_{1}, c_{2}^{1}, c_{2}^{2}, \pi^{M}, \pi^{D}\right)\right.$ such that $\left.0<\alpha<1,0<r<1, c_{1}>0, c_{2}^{1}>0, c_{2}^{2}>0, \pi^{M}>\pi^{D} \geq 0\right\}$.

As above, we restrict our attention to Region A, where both firms invest at every history. We find that all sharing patterns where firm 2 is the leader are monotonic although nonmonotonicity may arise in sharing patterns where firm 1 is the leader.

Proposition 5 Suppose that the firms' research costs are $\left(c_{1}, c_{2}^{1}\right)$ in stage 1 and $\left(c_{1}, c_{2}^{2}\right)$ in 
stage 2. Then, in Region A, every MPE sharing pattern with firm 2 as the leader is monotonic. If $c_{2}^{1} \geqslant c_{2}^{2}$, every MPE sharing pattern with firm 1 as the leader is monotonic. For some values of $c_{2}^{1}<c_{2}^{2}$, however, there exists a MPE with a non-monotonic sharing pattern.

The novel result in Proposition 5 is that if the firms share at $(2,1)$, they do not necessarily share at $(1,0) .{ }^{26}$ When firm 2 has increasing costs, the sharing patterns where firm 1 is the leader may be non-monotonic. To explore this, we derive an equilibrium in the appendix where the firms share at the four histories $(2,1),(1,2),(2,0)$ and $(0,2)$. From $(34)$ in the appendix, the sharing condition at $(1,0)$ is

$$
\beta\left(2 \pi^{D}+c_{1}+c_{2}^{2}\right)+(1-\beta)\left(c_{2}^{1}-c_{2}^{2}\right)>0,
$$

where $\beta=\frac{\alpha}{(3 \alpha+r)}$. The new term $c_{2}^{1}-c_{2}^{2}$ captures the change in investment costs when the lagging firm stops research on step 1 and begins research on step 2. If $c_{2}^{1}-c_{2}^{2}<0$, this is a loss and (8) does not always hold. When (8) fails, the firms share at $(2,1)$ but not at $(1,0)$. By not sharing at $(1,0)$, the firms prevent firm 2 from starting to work on step 2, where it would incur high research costs. If firm 1 subsequently completes step 2 , firm 2 will never have to work on it. The firms would attain even higher joint profits if firm 2 were simply to refrain from conducting further research at $(1,0)$. However, by assumption, the firms cannot agree to this.

Hence, the analysis reveals that the impact of research costs on sharing incentives depends on whether we are considering current or future research costs. While an increase in the firststage research cost of firm $2, c_{2}^{1}$, makes sharing at $(1,0)$ more attractive, an increase in the second-stage research cost, $c_{2}^{2}$, makes sharing at $(1,0)$ less attractive. This contrasts with our comparative statics conclusions from section 4.1, where an increase in $c$ always made sharing more attractive.

These results extend the results under symmetry, showing that the monotonicity result of section 4.1 is not a special phenomenon of symmetric environments. They describe what type of sharing dynamics we would expect to see in industries where there is a dominant research firm and in industries where different firms specialize in different stages of the research process. In most of the cases we considered, we have found that as firms approach the point of rivalry,

\footnotetext{
${ }^{26}$ Recall that in the symmetric model, the sharing condition at $(1,0)$, given by $(5)$, holds trivially.
} 
their incentives to cooperate break down. However, if the research costs of one of the firms increase over time, the firms may choose not to share earlier on, but choose to share later on when they are closer to product market competition. Thus, changes in research costs over time may lead to sharing dynamics that are not monotonic.

\section{$7 \quad$ Patent Policy}

We next discuss the impact of patent policy on the dynamics of sharing. So far we have assumed that once a firm successfully develops a research step, it can either keep the technology secret or patent it. If there is patenting, the lagging firm can develop a noninfringing technology that serves the same purpose and continues to face the same research cost. In this section, we assume that patenting increases the lagging firm's research cost by forcing it to work around the patent of the leader. Stronger patent policy (i.e., broader patent protection) may make it harder for rival firms to invent around (Gallini, 1992). ${ }^{27}$ Accordingly, we assume that a strengthening of patent policy increases the lagging firm's research cost. We show that stronger patent protection, as long as it does not cause exit by the lagging firm, increases the incentives to share. However, if stronger patent protection increases the incentives to exit, it may decrease the incentives to share. Thus, as in our basic model, the incentives to drop out play a crucial role in the results. ${ }^{28}$

We assume that both steps of the research process are patentable and, as soon as a firm successfully completes a stage, it gets a patent. The firms have symmetric $\operatorname{costs} c$ at the histories $(0,0)$ and $(1,1)$, when they are working towards the same research step. After one of the firms completes the next stage, the lagging firm cannot continue to work on the same research path because doing so would imply infringement. Hence, if it decides to stay in the game, it has two options. It can either make a licensing deal with the leader or switch to a more expensive research path with $\operatorname{cost} c^{P}>c$. On this more expensive path, the firm invests to complete the research process in a noninfringing way. ${ }^{29}$

\footnotetext{
${ }^{27}$ The concept of patent scope has been interpreted in several different ways in the literature on optimal patent policy. See Scotchmer (2004) for a discussion of the different models.

${ }^{28}$ Bar (2006) and Fershtman and Markovich (2006) also explore the impact of patent policy in a dynamic R\&D process, focusing on different research questions. Bar (2006) studies the strategic incentives to publish $R \& D$ results in a dynamic $R \& D$ process. Fershtman and Markovich (2006) study the effects of different patent policy regimes on the speed of innovation in an asymmetric dynamic $R \& D$ race.

${ }^{29}$ Hence, we assume that there are different research paths the firms can take to achieve the same research
} 
This set-up implies that the firms face asymmetric research costs at asymmetric histories. While in section 6 we have considered different types of firms, in this section we assume the firms are symmetric to start with, but they become asymmetric as the game progresses and the firms successfully develop the different research steps. We assume that patenting in both stages affects the research cost of the lagging firm in the same way by increasing it from $c$ to $c^{P}$.

As in the previous section, we focus on Region A and explore how the sharing incentives change over time and when the sharing patterns are monotonic in this region. ${ }^{30}$ The derivations are straightforward and available on request. Because the firms are not inherently asymmetric, we use the same monotonicity definition as the one in section 3 . The sharing condition at the histories $(2,1)$ and $(1,2)$ is given by

$$
2 \pi^{D}-\left(\pi^{M}-c^{P}\right)>0
$$

This is also the sharing condition at $(2,0)$ and $(0,2)$. When $(9)$ is satisfied, the firms share at all the future histories after $(1,0)$ and $(0,1)$. The sharing condition at $(1,0)$ and $(0,1)$ is given by

$$
\beta\left(\pi^{D}+c\right)+(1-\beta)\left(c^{P}-c\right)>0
$$

where $\beta=\frac{2 \alpha}{4 \alpha+r}$. ${ }^{31}$ The first term $\pi^{D}+c$ is the same as in (5), and is the benefit of sharing that arises when the lagging firm finishes earlier due to sharing. The second term is also a gain since $c^{P} \geq c$. This is the change in the firms' joint flow profits which arises when the lagging firm stops working to circumvent the patent on step 1 and instead conducts research on step 2. The condition (5) holds trivially, so the monotonicity property holds. Hence, sharing incentives decrease over time in environments where patenting makes research more costly for the lagging firm.

A policy to strengthen patent protection causes an increase in the cost parameter $c^{P}$. To analyze this, we consider how the cost parameter $c^{P}$ enters the sharing conditions $(9)$ and (10).

outcome and the different research paths correspond to different research costs. If one of the firms gets a patent, the follower has to switch to another research path to avoid infringement.

${ }^{30} \mathrm{As}$ in previous sections, Region $\mathrm{A}$ is defined by the drop out condition for the lagging firm at the history $(2,0, N S)$. It is straightforward to show that the lagging firm stays in the game at $(2,0, N S)$ if and only if $\pi^{D}>c^{P} \frac{r}{\alpha}\left(2+\frac{r}{\alpha}\right)$.

${ }^{31}$ Note that when $c^{P}=c$, this is the same condition as in the symmetric model. 
Since $c^{P}$ enters both conditions with a positive sign, a strengthening of patent policy increases the benefits from sharing. This is because the policy affects the lagging firm's outside option. Since the lagging firm has to incur higher research costs following the patenting decision of the leader, it will be willing to pay a higher licensing fee to the leader in exchange for the technology. Hence, with broader patent protection, we would expect the extent of sharing to increase because the firms can save on higher costs of research.

This conclusion however may not always be true if a strengthening of patent policy changes the investment decisions. If an increase in the lagging firm's research cost $c^{P}$ causes it to exit at some histories, we are in Region B. Here, a strengthening in patent policy increases the incentive for the lagging firm to exit. From the analysis in section 4.2, we know that the firms may decide against sharing to cause the lagging firm to exit. This is because the leading firm upon finishing will earn monopoly profits forever. In Region A, patents by definition do not confer monopoly profits forever. It is possible that a strengthening of patent policy would shift the game from Region A to Region B. In this case, the policy could reduce the extent of sharing. Moreover, if the new equilibrium is non-monotonic, sharing could break down early in the research process even if it does not break down at the end. Thus, in practice, predicting the effect of patent policy requires knowledge of whether exit is likely (as in a winner-take-all environment) or whether several firms could profitably pursue the research to its conclusion.

\section{Conclusion}

The paper considers the optimal pattern of knowledge sharing in the context of technological competition. We have analyzed how the incentives to share change over time as a research project reaches maturity. Developing a theoretical foundation for optimal sharing strategies has important implications for the design of optimal as well as efficient research environments.

The results show that both how close the firms are to product market competition and how intense that competition is shape the firms' sharing behavior. If product market competition is moderate and the lagging firm is expected never to drop out under rivalry, the incentives to share intermediate research outcomes decreases monotonically with progress. If the product market competition is intense and the lagging firm is expected to drop out, the incentives to share may increase with progress. 
The prevalence of sharing in early stages of research in certain industries, often attributed to efficiencies of internalizing spillovers, could be due in part to these competitive dynamics. Thus, to the extent that the competitive dynamics matter, the propensity to share in early stages would not indicate its higher value. The monotonicity result is also consistent with the existing evidence that direct competitors choose to limit the scope of their alliance to activities which can be considered to be further away from the product market (Oxley and Sampson, 2004).

As robustness check, we have investigated whether the monotonicity result continues to hold if we have an $N$-step research process, if the firms are asymmetric, and if patenting increases the research cost of the lagging firm. These results show us under what types of conditions we would expect the monotonicity result to continue to hold. Specifically, we have shown that the monotonicity result may be violated if there is asymmetry across the different stages of research for one of the firms.

One assumption we have made in our analysis is that the lagging firm has no bargaining power. Consider how a different distribution of bargaining power between the two firms would affect the results. The distribution of bargaining power does not affect the joint payoffs, but it affects the individual payoffs. Hence, with a change in the firms' bargaining powers, the incentives to share would not be affected, ceteris paribus, because the sharing decisions are made based on joint profits. However, since the individual payoffs of the firms would change, the investment incentives would change. In particular, Region A (where neither firm drops out at any of the histories) would expand to include more parameters because the lagging firm would have a greater incentive to stay in the game.

Our results suggest new directions for empirical research on innovation. Although there is a large literature on research alliances, there has been little prior empirical research focusing on the dynamics of these alliances. Our theoretical work focuses on the dynamics of sharing where the intensity of product market competition, the difficulty of research, and the impatience of firms are the key factors. Future research could address whether these dynamics can be identified and empirically distinguished from the impact of other dynamic variables, such as the intensity of spillovers, financing issues, and the degree of antitrust risk, which are also likely shape the patterns of sharing in industries where innovation is important. The role played by 
each factor may depend on the industry and the nature of the research. ${ }^{32}$

Our results offer insights to guide policy-making in innovation environments. Since the 1980s, governments in the US and in Europe have used subsidies, tolerant antitrust treatment, and government-industry partnerships to promote joint R\&D projects. Considering the dynamics of sharing incentives and distinguishing between the factors which may shape these incentives would help in determining under what circumstances such policies are necessary and whether they should be directed towards early vs. later stage research. If, as in our model, product market competition drives the dynamics of sharing, the monotonicity result stated in Proposition 1 implies that in less competitive industries (where lagging firms pursue duopoly profits rather than exiting), firms are likely to have lower incentives to share in later stages of research than in early stages. In this case, policies that encourage sharing in later stages when private incentives to share are the weakest may have the greatest value. In contrast, Proposition 2 implies that in more competitive industries, such as industries with a winner-take-all structure, firms may have lower incentives to share in early stages of research than in later stages. In this case, policies that encourage sharing in early stages in order to keep lagging firms in the market may have the greatest value.

\footnotetext{
${ }^{32}$ For example, Lerner and Merges (1998) find that in the biotechnology industry, it is the R\&D firms' need for financing which may cause alliances to form at the earlier stages of research.
} 


\section{References}

[1] Bar, T. 2006. "Defensive Publications in an R\&D Race," Journal of Economics 83 Management Strategy, 15(1), 229-254.

[2] D'Aspremont, C. and A. Jacquemin. 1988. "Cooperative and Noncooperative R\&D in Duopoly with Spillovers," American Economic Review, 78(5), 1133-1137.

[3] Cabral, L. M. B. 2003. "R\&D Competition When Firms Choose Variance," Journal of Economics and Management Strategy, 12(1), 139-150.

[4] Choi, J.P. 1993. "Cooperative R\&D with Product Market Competition," International Journal of Industrial Organization, 11, 553-571.

[5] Fershtman, C. and S. Markovich. 2006. "Patents, Imitation and Licensing in an Asymmetric Dynamic R\&D Race," CEPR Discussion Paper No. 5481.

[6] Gallini, N. T. 1992. "Patent Policy and Costly Imitation," Rand Journal of Economics, $23(1), 52-63$.

[7] Grossman, G. M. and C. Shapiro. 1986. "Optimal Dynamic R\&D Programs," Rand Journal of Economics, 17(4), 581-593.

[8] Grossman, G. M. and C. Shapiro. 1987. "Dynamic R\&D Competition," Economic Journal, 97(386), 372-387.

[9] Judd, K. L. 2003. "Closed-Loop Equilibrium in a Multi-Stage Innovation Race," Economic Theory, 21, 673-695.

[10] Kamien, M. I. 1992. "Patent Licensing," in R. J. Aumann and S. Hart (eds.), Handbook of Game Theory with Economic Applications, Volume 1, Elsevier Science.

[11] Kamien, M. I., E. Muller and I. Zang. 1992. "Research Joint Ventures and R\&D Cartels," American Economic Review, 82(5), 1293-1306.

[12] Katz, M. L. 1986. "An Analysis of Cooperative Research and Development," Rand Journal of Economics, 17(4), 528-542. 
[13] Katz, M. L. and J. A. Ordover. 1990. "R and D Cooperation and Competition," Brookings Papers on Economic Activity, Microeconomics, 137-203.

[14] Khanna, T. and M. Iansiti. 1997. "Firm Asymmetries and Sequential R\&D: Theory and Evidence from the Mainframe Computer Industry," Management Science, 43(4), 405-421.

[15] Lerner, J. and R. P. Merges. 1998. "The Control of Technology Alliances: An Empirical Analysis of the Biotechnology Industry," Journal of Industrial Economics, 46(2), 125-156.

[16] Majewski, S. 2004. "How Do Consortia Organize Collaborative R\&D? Evidence from the National Cooperative Research Act," Harvard Law School, Olin Center for Law, Economics, and Business, Discussion Paper No. 483.

[17] Northrup, J. 2005. "The Pharmaceutical Sector," in L. R. Burns (ed.), The Business of Healthcare Innovation, Cambridge University Press, New York.

[18] Oxley, J. and R. Sampson. 2004. "The Scope and Governance of International R\&D Alliances," Strategic Management Journal, 25(8-9), 723-750.

[19] Scotchmer, S. 2004. Innovation and Incentives. Cambridge, MA: MIT Press.

[20] Scotchmer, S. and J. Green. 1990. "Novelty and Disclosure in Patent Law," Rand Journal of Economics, 21(1), 131-146.

[21] Severinov, S. 2001. "On Information Sharing and Incentives in R\&D," Rand Journal of Economics, 32(3), 542-564.

[22] Singh, N. and X. Vives. 1984. "Price and Quantity Competition in a Differentiated Duopoly," Rand Journal of Economics, 15, 546-554.

[23] Vonortas, N. 1994. "Inter-firm Cooperation with Imperfectly Appropriable Research," International Journal of Industrial Organization, 12, 413-435.

[24] Wang, X. H. 2002. "Fee versus Royalty Licensing in a Differentiated Cournot Duopoly," Journal of Economics and Business, 54, 253-266. 


\section{Appendix}

\section{A Proof of Lemma 1}

We must show that Region A consists of all parameters such that $\pi^{D} \geq c \frac{r}{\alpha}\left(2+\frac{r}{\alpha}\right)$. In a companion appendix, we prove this by solving for all of the equilibria (see footnote 17). Here, instead, we focus on the payoff that a firm would earn by conducting two steps of research on its own and producing in the output market as a duopolist. This is a lower bound on any firm's payoff at any history and in any equilibrium. In Region A, the payoff of the lagging firm at $(2,0)$ equals this payoff. If the firms decide not to share at $(2,0)$ and $(2,1)$, this is clearly the case. If the firms decide to share at $(2,0)$ and $(2,1)$, then because the lagging firm has no bargaining power, its payoff is the same as if they do not share.

We compute this payoff by working backwards. After completing the two steps of research, the firm produces output as a duopolist to earn $\widetilde{\pi}^{D}=\frac{\pi^{D}}{r}$. To complete the second step of research, the firm invests a flow cost of $c$ and in each instant the probability of success is $\alpha$. The firm's expected payoff is $\int_{0}^{\infty} e^{-(\alpha+r) t}\left(\alpha \widetilde{\pi}^{D}-c\right) d t=\frac{\alpha \widetilde{\pi}^{D}-c}{\alpha+r}$. To complete the first step of research, the firm again invests a flow cost of $c$ and the hazard rate is again $\alpha$. The firm's expected payoff is $\int_{0}^{\infty} e^{-(\alpha+r) t}\left(\alpha\left(\frac{\alpha \widetilde{\pi}^{D}-c}{\alpha+r}\right)-c d t\right)=\frac{\alpha\left(\frac{\alpha \tilde{\pi}^{D}-c}{\alpha+r}\right)-c}{\alpha+r}$. This payoff is strictly positive if and only if

$$
\pi^{D}>c \frac{r}{\alpha}\left(2+\frac{r}{\alpha}\right)
$$

which is the inequality that defines Region A.

\section{B Proof of Proposition 1}

In Region A, by definition, no firm ever drops out of the game. To solve for the MPE, we only need to determine whether firms share at the six asymmetric histories. We derive the equilibrium sharing conditions for $(1,0),(2,0)$ and $(2,1)$. The three mirror histories $(0,1),(0,2)$, and $(1,2)$ have the same analysis. To derive the sharing conditions, we use backwards induction to solve for the MPE. To prove the proposition, we compare the equilibrium sharing conditions at $(1,0)$ and $(2,1)$ for every MPE.

The last history is $(2,2)$. At $(2,2)$, each firm produces output and earns discounted duopoly 
profits of

$$
V_{1}(2,2)=V_{2}(2,2)=\tilde{\pi}^{D}
$$

Working backwards, the next history is $(2,1)$. The firms are willing to share at $(2,1)$ iff this maximizes their joint profits. The sharing condition (2) is

$$
V_{J}(2,2)>V_{J}(2,1 ; N S)
$$

Joint profits under sharing are $V_{J}(2,2)=V_{1}(2,2)+V_{2}(2,2)=2 \widetilde{\pi}^{D}$. Joint profits under no sharing are

$$
V_{J}(2,1 ; N S)=V_{1}(2,1, N S)+V_{2}(2,1, N S)=\frac{\pi^{M}+2 \alpha \widetilde{\pi}^{D}-c}{\alpha+r},
$$

where

$$
V_{1}(2,1 ; N S)=\frac{\pi^{M}+\alpha V_{1}(2,2)}{\alpha+r}=\frac{\pi^{M}+\alpha \widetilde{\pi}^{D}}{\alpha+r}
$$

since firm 1 earns monopoly profits until firm 2 completes the second step and

$$
V_{2}(2,1 ; N S)=\frac{\alpha V_{2}(2,2)-c}{\alpha+r}=\frac{\alpha \widetilde{\pi}^{D}-c}{\alpha+r}
$$

since firm 2 invests until it completes the second step.

The sharing condition (13) simplifies to $2 \widetilde{\pi}^{D}(\alpha+r)>\pi^{M}+2 \alpha \widetilde{\pi}^{D}-c$ or

$$
2 \pi^{D}-\left(\pi^{M}-c\right)>0
$$

This condition holds, strictly fails, or holds as an equality. We consider each possibility in turn.

Case 1: The sharing condition at $(2,1)$ holds. For parameter values such that the sharing condition (16) holds, the firms share step 2 at $(2,1)$. Before considering the sharing decision at $(1,0)$, we need to see whether the firms share step 1 at $(2,0)$. The sharing condition (2) is $V_{J}(2,1)>V_{J}(2,0 ; N S)$. Joint profits under sharing are $V_{J}(2,1)=V_{J}(2,2)=2 \widetilde{\pi}^{D}$ since the firms share at $(2,1)$ after sharing at $(2,0)$. Joint profits under no sharing are

$$
\begin{aligned}
V_{J}(2,0 ; N S) & =V_{1}(2,0 ; N S)+V_{2}(2,0 ; N S) \\
& =\frac{\pi^{M}+\alpha V_{1}(2,1)}{\alpha+r}+\frac{\alpha V_{2}(2,1)-c}{\alpha+r}=\frac{\pi^{M}+\alpha V_{J}(2,1)-c}{\alpha+r}=\frac{\pi^{M}+\alpha 2 \widetilde{\pi}^{D}-c}{\alpha+r} .
\end{aligned}
$$


The sharing condition $V_{J}(2,1)>V_{J}(2,0 ; N S)$ simplifies to

$$
\begin{aligned}
2 \tilde{\pi}^{D}(\alpha+r) & >\pi^{M}+2 \alpha \tilde{\pi}^{D}-c \\
c & >\pi^{M}-2 \pi^{D} .
\end{aligned}
$$

This is condition (16), which we have assumed to hold. Hence, the firms share step 1 at $(2,0)$. The joint payoffs are $2 \widetilde{\pi}^{D}$.

At $(1,0)$, the sharing condition $(2)$ is $V_{J}(1,1)>V_{J}(1,0 ; N S)$. Joint profits under sharing are $V_{J}(1,1)=2 V_{1}(1,1)$ where

$$
V_{1}(1,1)=\frac{\alpha V_{1}(1,2)+\alpha V_{1}(2,1)-c}{2 \alpha+r}=\frac{\alpha V_{J}(2,1)-c}{2 \alpha+r}=\frac{2 \alpha \widetilde{\pi}^{D}-c}{2 \alpha+r}
$$

Joint profits under no sharing are

$$
V_{J}(1,0 ; N S)=\frac{\alpha V_{J}(2,0)+\alpha V_{J}(1,1)-2 c}{2 \alpha+r}=\frac{2 \alpha \tilde{\pi}^{D}+\alpha V_{J}(1,1)-2 c}{2 \alpha+r} .
$$

The sharing condition simplifies to

$$
(2 \alpha+r) V_{J}(1,1)>2 \alpha \widetilde{\pi}^{D}+\alpha V_{J}(1,1)-2 c .
$$

Substituting for $V_{J}(1,1)$ in $(18)$ we get

$$
\pi^{D}+c>0
$$

which is trivially true. This proves the monotonicity result for all parameter values for which the sharing condition (16) holds. In the unique MPE for these parameter values, the firms share at $(2,1)$ and $(1,0)$. The sharing pattern is $(\mathrm{S}, \mathrm{S})$.

Case 2. The sharing condition at $(2,1)$ fails strictly. For parameter values such that the sharing condition (16) strictly fails, the firms do not share at $(2,1)$. Before considering the sharing decision at $(1,0)$, we need to see whether the firms share at $(2,0)$. The sharing condition $(2)$ is $V_{J}(2,1)>V_{J}(2,0 ; N S)$. Joint profits are under no sharing are

$$
\begin{aligned}
V_{J}(2,0 ; N S) & =V_{1}(2,0 ; N S)+V_{2}(2,0 ; N S) \\
& =\frac{\pi^{M}+\alpha V_{1}(2,1)}{\alpha+r}+\frac{\alpha V_{2}(2,1)-c}{\alpha+r}=\frac{\pi^{M}+\alpha V_{J}(2,1)-c}{\alpha+r} .
\end{aligned}
$$

The sharing condition simplifies to

$$
V_{J}(2,1)>\frac{\pi^{M}+\alpha V_{J}(2,1)-c}{\alpha+r}
$$


Since the firms do not share at $(2,1)$, we can substitute for $V_{J}(2,1)$ from (14). Simplifying, we get $c>\pi^{M}-2 \pi^{D}$. This is the same as condition (16) which does not hold. Hence, the firms do not share step 1 at $(2,0)$.

At $(1,0)$, the sharing condition $(2)$ is $V_{J}(1,1)>V_{J}(1,0 ; N S)$. Joint profits under no sharing are

$$
V_{J}(1,0 ; N S)=\frac{\alpha V_{J}(2,0)+\alpha V_{J}(1,1)-2 c}{2 \alpha+r} .
$$

The sharing condition simplifies to $(\alpha+r) V_{J}(1,1)>\alpha V_{J}(2,0)-2 c$. We can substitute for $V_{J}(1,1)=2 V_{2}(1,1)$. We have

$$
V_{J}(1,1)=2 \frac{\alpha V_{2}(1,2)+\alpha V_{2}(2,1)-c}{2 \alpha+r}=2 \frac{\alpha V_{J}(2,1)-c}{2 \alpha+r}=2 \frac{\alpha\left(\pi^{M}+2 \alpha \tilde{\pi}^{D}\right)-c(2 \alpha+r)}{(2 \alpha+r)(\alpha+r)},
$$

where the last equality follows from (14). Since there is no sharing at either $(2,0)$ or $(2,1)$, we use (14) to get

$$
V_{J}(2,0)=\frac{\pi^{M}+\alpha V_{J}(2,1)-c}{\alpha+r}=\frac{(2 \alpha+r) \pi^{M}+2 \alpha^{2} \tilde{\pi}^{D}-c(2 \alpha+r)}{(\alpha+r)^{2}} .
$$

Substituting for $V_{J}(1,1)$ and $V_{J}(2,0)$, the sharing condition simplifies to

$$
c>\left(\pi^{M}-2 \pi^{D}\right)-\frac{2(\alpha+r)^{2}}{(2 \alpha+r)^{2}}\left(\pi^{M}-\pi^{D}\right) .
$$

Since $\pi^{M}>\pi^{D}$, this condition is easier to satisfy than (16). For parameter values such that the sharing condition (21) holds, there is a unique MPE such that the firms share at $(1,0)$ but not at $(2,1)$. The sharing pattern is $(\mathrm{S}, \mathrm{NS})$. For parameter values such that the sharing condition (21) strictly fails, there is a unique MPE such that the firms do not share at either $(1,0)$ or $(2,1)$. The sharing pattern is (NS,NS). For parameter values such that the sharing condition (21) holds with equality, there are two MPE that differ based on whether the firms choose $\mathrm{S}$ or NS at $(1,0)$. The sharing pattern is either $(\mathrm{S}, \mathrm{NS})$ or $(\mathrm{NS}, \mathrm{NS})$.

Case 3. The sharing condition at $(2,1)$ holds with equality. When $c=\pi^{M}-2 \pi^{D}$, the firms are indifferent between sharing and not sharing at $(2,1)$. We know from above that the sharing condition at $(2,0)$ is the same as the sharing condition at $(2,1)$, so the firms are indifferent between sharing and not sharing at $(2,0)$. There are multiple equilibria because the firms may choose either S or NS at $(2,0)$. Regardless of their choices, the sharing condition at $(1,0)$ is given by both (19) and (21) which coincide and hold trivially. Hence, the sharing pattern is either $(\mathrm{S}, \mathrm{NS})$ or $(\mathrm{S}, \mathrm{S})$. 


\section{Calculation of the licensing fees}

The leading firm sets the licensing fee according to equation (1), so that the lagging firm is just indifferent between sharing and not sharing. At $(2,1)$, the licensing fee is

$$
F(2,1)=V_{2}(2,2)-V_{2}(2,1 ; N S)=\frac{\pi^{D}+c}{\alpha+r}
$$

where the last equality makes use of $(12)$ and $(15)$. At $(1,0)$, the licensing fee is

$$
F(1,0)=V_{2}(1,1)-V_{2}(1,0 ; N S)
$$

We can substitute for $V_{2}(1,1)$ from $(17) . V_{2}(1,0 ; N S)$ is given by

$$
V_{2}(1,0 ; N S)=\frac{\alpha V_{2}(1,1)+\alpha V_{2}(2,0)-c}{2 \alpha+r} .
$$

Since the lagging firm has no bargaining power at $(2,0)$, its profit is $V_{2}(2,0 ; N S)$ even though the firms share at $(2,0)$. Similarly, its profit at $(2,1)$ is $V_{2}(2,1 ; N S)$ even though the firms share at $(2,1)$. Using $(15)$, we have

$$
V_{2}(2,0)=V_{2}(2,0 ; N S)=\frac{\alpha V_{2}(2,1)-c}{\alpha+r}=\frac{\alpha^{2} \widetilde{\pi}^{D}-c(2 \alpha+r)}{(\alpha+r)^{2}}
$$

Hence, $F(1,0)$ simplifies to

$$
F(1,0)=\left(\frac{\pi^{D}+c}{\alpha+r}\right)\left(\frac{5+6 \frac{r}{\alpha}+2\left(\frac{r}{\alpha}\right)^{2}}{4+8 \frac{r}{\alpha}+5\left(\frac{r}{\alpha}\right)^{2}+\left(\frac{r}{\alpha}\right)^{3}}\right) .
$$

Comparing the fees $F(1,0)$ and $F(2,1)$, we find that $F(2,1)>F(1,0)$ iff $\frac{r}{\alpha}$ is above a cut-off of approximately $\frac{r}{\alpha} \cong 0.325$.

\section{Proof of Proposition 2}

We solve for the equilibria of the game for all parameter values in a companion appendix (see footnote 17). Here, we derive the non-monotonic equilibrium discussed in the paper. In the companion appendix, this region is labeled as Region 6. The equilibria for other parameter values are solved similarly.

We solve the game in the following region of parameters: $c \frac{r}{\alpha}\left(\frac{3}{2}+\frac{r}{2 \alpha}\right)<\pi^{D}<c \frac{r}{\alpha}\left(2+\frac{r}{\alpha}\right)$ and $2 \pi^{D}\left(\frac{2 \alpha+2 r}{2 \alpha+r}\right)+c\left(\frac{2 r}{2 \alpha+r}\right)<\pi^{M}<2 \pi^{D}+c$. This is a subregion of Region B. A straightforward calculation shows that the region is non-empty if and only if $\frac{r}{\alpha}<\frac{1}{2}(\sqrt{5}-1)$ where $\frac{1}{2}(\sqrt{5}-1) \simeq 0.62$. 
To find an equilibrium, we work backwards from the end of the game. We derive the continuation profits at each history and solve for the equilibrium actions. For symmetric histories such as $(2,1)$ and $(1,2)$, we analyze only one of the histories as the analysis is the same for both.

The last history is the history $(2,2)$. At this history, the firms produce output and each earns discounted duopoly profits of $V_{i}(2,2)=\widetilde{\pi}^{D}$. Working backwards, the next history is $(2,1)$. The firms are willing to share at $(2,1)$ iff this maximizes their joint profits. The sharing condition $(2)$ is $V_{J}(2,2)>V_{J}(2,1 ; N S)$. The payoff $V_{J}(2,1 ; N S)$ depends on whether firm 2 invests. If firm 2 invests at $(2,1 ; N S)$, its continuation profit is

$$
V_{2}(2,1 ; N S)=\frac{\alpha \tilde{\pi}^{D}-c}{\alpha+r} .
$$

This payoff is positive because by assumption $\pi^{D}>c \frac{r}{\alpha}$. Hence, firm 2 invests at $(2,1 ; N S)$.

Since firm 2 invests at $(2,1 ; N S)$, the analysis of the sharing condition is the same as the one in section (B), we do not repeat here. The firms share at $(2,1)$ iff $(16)$ holds. This condition holds in this region and the firms share step 2 at $(2,1)$.

At the history $(1,1)$, each firm has one success. There is no sharing decision to be made. The firms must, however, decide whether to invest to develop the second step. Assuming firm 1 invests, firm 2 will also invest if

$$
V_{2}(1,1)=\frac{\alpha V_{2}(2,1)+\alpha V_{2}(1,2)-c}{2 \alpha+r}=\frac{\alpha V_{J}(2,1)-c}{2 \alpha+r}>0 .
$$

Since the firms share at $(2,1), V_{J}(2,1)=2 \widetilde{\pi}^{D}$. Substituting we get

$$
V_{2}(1,1)=\frac{2 \alpha \tilde{\pi}^{D}-c}{2 \alpha+r}>0,
$$

which simplifies to $\pi^{D}>\frac{c r}{2 \alpha}$. Since this condition holds by assumption in this region, firm 2 invests. Hence, each firm invests at $(1,1)$ if the other does.

If firm 1 does not invest at $(1,1)$, the new history is $(X, 1)$. Firm 2 invests if

$$
V_{2}(X, 1)=\frac{\alpha V_{2}(X, 2)-c}{\alpha+r}=\frac{\alpha \widetilde{\pi}^{M}-c}{\alpha+r}>0,
$$

where $V_{2}(X, 2)=\widetilde{\pi}^{M}$ because firm 2 produces output as a monopolist at $(X, 2)$. The condition simplifies to $\pi^{M}>c \frac{r}{\alpha}$, which holds because $\pi^{M}>\pi^{D}$ and in this region $\pi^{D}>c \frac{r}{\alpha}$. Hence, firm 2 invests at $(X, 1)$. It follows that both firms invest at $(1,1)$. 
At the history $(2,0)$, the sharing condition is $V_{J}(2,1)>V_{J}(2,0 ; N S)$. The payoff $V_{J}(2,0 ; N S)$ depends on whether firm 2 invests. Firm 2 invests iff

$$
V_{2}(2,0 ; N S)=\frac{\alpha V_{2}(2,1)-c}{\alpha+r}>0 .
$$

We know from Lemma 1 that this condition simplifies to

$$
\pi^{D}>c \frac{r}{\alpha}\left(2+\frac{r}{\alpha}\right)
$$

which fails in this region, so firm 2 drops out at $(2,0)$ if the firms do not share.

At $(2,0)$, joint profits under sharing are $V_{J}(2,1)=2 \widetilde{\pi}^{D}$ since if the firms share, the game reaches the history $(2,1)$ and the firms share step 2 . Joint profits under no sharing are $V_{J}(2,0 ; N S)=V_{1}(2, X)=\widetilde{\pi}^{M}$ since firm 2 drops out of the game if the firms do not share. Thus, the sharing condition at $(2,0)$ simplifies to

$$
2 \pi^{D}-\pi^{M}>0
$$

In this region, we have that $\pi^{M}>2 \pi^{D}$. Hence, the firms do not share at $(2,0)$. The lagging firm then drops out of the game.

Working backwards from either $(2,0)$ or $(1,1)$, we next consider the history $(1,0)$. At this history, firm 1 has one success and firm 2 has no successes. The sharing condition is $V_{J}(1,1)>V_{J}(1,0 ; N S)$. The payoff $V_{J}(1,0 ; N S)$ depends on whether each firm invests. If firm 1 invests, firm 2 also invests if

$$
V_{2}(1,0 ; N S)=\frac{\alpha V_{2}(1,1)+\alpha V_{2}(2,0)-c}{2 \alpha+r}>0
$$

We can substitute for $V_{2}(1,1)$ from $(25)$. Moreover, $V_{2}(2,0)=0$ since the firms do not share at $(2,0)$ and the lagging firm drops out. After substituting and simplifying, (28) becomes

$$
\pi^{D}>c \frac{r}{\alpha}\left(\frac{3}{2}+\frac{r}{2 \alpha}\right) \text {. }
$$

This holds in the region, so the lagging firm 2 invests at $(1,0 ; N S)$ if firm 1 does. It is straightforward to show that the leading firm 1 also invests at $(1,0 ; N S)$ if firm 2 invests. If firm 2 does not invest, the history becomes $(1, X)$ and the leading firm invests as shown above. It follows that the leading firm invests at $(1,0 ; N S)$ whether or not the lagging firm invests. Thus, both firms invest at $(1,0 ; N S)$. 
At $(1,0)$, joint profits under no sharing are

$$
V_{J}(1,0 ; N S)=\frac{\alpha V_{J}(2,0)+\alpha V_{J}(1,1)-2 c}{2 \alpha+r}=\frac{\alpha \tilde{\pi}^{M}+\alpha V_{J}(1,1)-2 c}{2 \alpha+r} .
$$

The sharing condition, $V_{J}(1,1)>V_{J}(1,0 ; N S)$, simplifies to

$$
\alpha \widetilde{\pi}^{M}+\alpha V_{J}(1,1)-2 c<(2 \alpha+r) V_{J}(1,1)
$$

Substituting for $V_{J}(1,1)=2 V_{2}(1,1)$ from $(25)$ and simplifying, the sharing condition at $(1,0)$ is

$$
\pi^{M}<2 \pi^{D}\left(\frac{2 \alpha+2 r}{2 \alpha+r}\right)+c\left(\frac{2 r}{2 \alpha+r}\right)
$$

This inequality fails in the region, so the firms do not share at $(1,0)$.

At the history $(0,0)$, assuming firm 2 invests, firm 1 will also invest if

$$
V_{1}(0,0)=\frac{\alpha V_{1}(1,0 ; N S)+\alpha V_{1}(0,1 ; N S)-c}{2 \alpha+r}=\frac{\alpha V_{J}(1,0 ; N S)-c}{2 \alpha+r}>0
$$

Substituting from (29) and (25), we get

$$
4 \alpha \pi^{D}+(2 \alpha+r) \pi^{M}>(4 \alpha+r)(2 \alpha+r) \frac{r}{\alpha^{2}} c+2 c r .
$$

Since $\pi^{M}>2 \pi^{D}$ in this region, the condition holds if

$$
(8 \alpha+2 r) \pi^{D}>(4 \alpha+r)(2 \alpha+r) \frac{r}{\alpha^{2}} c+2 c r .
$$

Since $\pi^{D}>c \frac{r}{\alpha}\left(\frac{3}{2}+\frac{r}{2 \alpha}\right)$ in this region, the condition holds if

$$
(8 \alpha+2 r)\left(\frac{3}{2}+\frac{r}{2 \alpha}\right) \frac{r}{\alpha} c>(4 \alpha+r)(2 \alpha+r) \frac{r}{\alpha^{2}} c+2 c r .
$$

This simplifies to $2 \alpha(2 \alpha+r)>0$, which always holds. Hence, firm 1 invests at $(0,0)$ if firm 2 invests.

Assuming firm 2 does not invest, the history becomes $(0, X)$. Firm 1 invests if

$$
V_{2}(0, X)=\frac{\alpha V_{2}(1, X)-c}{\alpha+r}=\frac{\alpha\left(\frac{\alpha \widetilde{\pi}^{M}-c}{\alpha+r}\right)-c}{\alpha+r}>0,
$$

where we have substituted for $V_{2}(1, X)$ from (26). Simplifying we get

$$
\pi^{M}>c \frac{r}{\alpha}\left(2+\frac{r}{\alpha}\right) .
$$

In this region, we have that $\pi^{M}>2 \pi^{D}$ and $\pi^{D}>c \frac{r}{\alpha}\left(\frac{3}{2}+\frac{r}{2 \alpha}\right)$. These two conditions together imply that (31) holds. Hence, firm 1 invests at $(0, X)$. It follows that both firms invest at $(0,0)$. This completes the derivation of the equilibrium. The equilibrium is unique. 


\section{E Proof of Proposition 4}

The proof is a straightforward generalization of our results for Region A of the basic model. ${ }^{33}$ To save space, we do not present a complete proof. Instead, we focus on the subregion of Region A where, due to the asymmetry in their research costs, the firms share at $(2,1)$, but not at $(1,2) \cdot{ }^{34}$ We solve the game backwards. At $(2,1)$, the sharing condition is $V_{J}(2,2)>$ $V_{J}(2,1 ; N S)$. This yields

$$
2 \widetilde{\pi}^{D}>V_{J}(2,1 ; N S)=\frac{\pi^{M}+\alpha 2 \widetilde{\pi}^{D}-c_{2}}{\alpha+r} .
$$

This simplifies to $c_{2}>2 \pi^{D}-\pi^{M}$. Similarly, the firms share at $(1,2)$ if $c_{1}>2 \pi^{D}-\pi^{M}$. From now on we consider the subregion of Region A such that $c_{2}>\pi^{M}-2 \pi^{D}>c_{1}$. In this subregion, the firms share at $(2,1)$, but not at $(1,2)$. At $(2,0)$, the sharing condition is

$$
V_{J}(2,1)>V_{J}(2,0 ; N S)=\frac{\pi^{M}+\alpha V_{J}(2,1)-c_{2}}{\alpha+r} .
$$

Using $V_{J}(2,1)=2 \widetilde{\pi}^{D}$, this simplifies to $c_{2}>2 \pi^{D}-\pi^{M}$. This holds, so the firms share at $(2,0)$.

At $(0,2)$, the sharing condition is

$$
V_{J}(1,2)>V_{J}(0,2 ; N S)=\frac{\pi^{M}+\alpha V_{J}(1,2)-c_{1}}{\alpha+r} .
$$

Using

$$
V_{J}(1,2)=V_{J}(1,2 ; N S)=\frac{\pi^{M}+\alpha 2 \tilde{\pi}^{D}-c_{1}}{\alpha+r},
$$

the sharing condition simplifies to $c_{1}>2 \pi^{D}-\pi^{M}$. This does not hold, so the firms do not share at $(0,2)$.

At $(1,0)$, the sharing condition is $V_{J}(1,1)>V_{J}(1,0 ; N S)$. Joint profits at $(1,1)$ are

$$
V_{J}(1,1)=\frac{\alpha V_{J}(2,1)+\alpha V_{J}(1,2)-c_{2}-c_{1}}{2 \alpha+r} .
$$

Joint profits at $(1,0 ; N S)$ are

$$
V_{J}(1,0 ; N S)=\frac{\alpha V_{J}(1,1)+\alpha V_{J}(2,0)-c_{2}-c_{1}}{2 \alpha+r} .
$$

\footnotetext{
${ }^{33}$ Region $\mathrm{A}$ is the set of parameters such that $\pi^{D} \geq \frac{c_{2} r}{\alpha}\left(2+\frac{r}{\alpha}\right)$. This condition is the drop out condition for firm 2 (the inefficient firm) at the history $(2,0)$. The proof is similar to Lemma 1.

${ }^{34}$ When the firms do not share at either $(2,1)$ or $(1,2)$, the sharing pattern is monotonic regardless of the sharing decisions at $(1,0)$ and $(0,1)$. When the firms share at both $(2,1)$ and $(1,2)$, the derivation of the result is a straightforward generalization of the symmetric case.
} 
Substituting for $V_{J}(2,0)=V_{J}(2,1)=2 \widetilde{\pi}^{D}$ and $V_{J}(1,2)=V_{J}(1,2, N S)=\frac{\pi^{M}+\alpha 2 \widetilde{\pi}^{D}-c_{1}}{\alpha+r}$, the sharing condition at $(1,0)$ simplifies to $\pi^{M}+c_{2}>0$. This holds trivially, so the firms share at $(1,0)$. Thus, the monotonicity property holds for firm 1 in the subregion.

Because the firms do not share at $(1,2)$, the monotonicity property holds for firm 2 whether or not the firms share at $(0,1)$ in the subregion. The sharing condition at $(0,1)$ is $V_{J}(1,1)>$ $V_{J}(0,1 ; N S)$ where

$$
V_{J}(0,1 ; N S)=\frac{\alpha V_{J}(1,1)+\alpha V_{J}(0,2)-c_{2}-c_{1}}{2 \alpha+r} .
$$

Using (32) and substituting for $V_{J}(2,1)=2 \widetilde{\pi}^{D}, V_{J}(1,2, N S)=\frac{\pi^{M}+\alpha 2 \widetilde{\pi}^{D}-c_{1}}{\alpha+r}$, and $V_{J}(0,2)=$ $V_{J}(0,2, N S)=\frac{\pi^{M}+\alpha V_{J}(1,2)-c_{1}}{\alpha+r}$, the sharing condition at $(0,1)$ simplifies to

$$
c_{2}(\alpha+r)^{2}+\left(2 \pi^{D}+c_{1}\right)(2 \alpha+r)^{2}-\pi^{M} \alpha(3 \alpha+2 r)>0
$$

This can be rewritten as

$$
\frac{(\alpha+r)^{2}}{(2 \alpha+r)^{2}}\left(2 \pi^{D}+c_{1}+c_{2}\right)+\left(1-\frac{(\alpha+r)^{2}}{(2 \alpha+r)^{2}}\right)\left(2 \pi^{D}+c_{1}-\pi^{M}\right)>0 .
$$

It is straightforward to show using the other constraints that define this subregion that condition (33) always holds. Thus, the firms share at $(1,0)$ and the sharing pattern is (S,NS).

\section{F Proof of Proposition 5}

The proof is a straightforward generalization of our results for Region A of the basic model. ${ }^{35}$ To save space, we do not present a complete proof. Instead, we show why the monotonicity property for firm 1 does not always hold in Region A and derive the equations discussed in the text.

We solve the game by working backwards through the histories. At $(2,1)$, the sharing condition is

$$
V_{J}(2,2)>V_{J}(2,1 ; N S)=\frac{\pi^{M}+\alpha 2 \tilde{\pi}^{D}-c_{2}^{2}}{\alpha+r} .
$$

Using $V_{J}(2,2)=2 \widetilde{\pi}^{D}$, this simplifies to $2 \pi^{D}-\left(\pi^{M}-c_{2}^{2}\right)>0$.Similarly, the firms share at $(1,2)$ if and only if $2 \pi^{D}-\left(\pi^{M}-c_{1}\right)>0$. From now on, we consider the subregion of

\footnotetext{
${ }^{35}$ Here, Region A is the set of parameters such that $\pi^{D} \geq \max \left\{\frac{c_{1} r}{\alpha}\left(2+\frac{r}{\alpha}\right), \frac{c_{2}^{1} r}{\alpha}\left(1+\frac{r}{\alpha}\right)+\frac{c_{2}^{2} r}{\alpha}\right\}$. When this condition holds, firm 1 does not drop out at $(0,2)$ and firm 2 does not drop out at $(2,0)$. The proof is a straightforward generalization of Lemma 1.
} 
Region A where both of these conditions hold, so the firms share at $(2,1)$ and $(1,2)$. We have $V_{J}(2,1)=V_{J}(1,2)=2 \widetilde{\pi}^{D}$.

At $(2,0)$, the sharing condition is

$$
V_{J}(2,1)>V_{J}(2,0 ; N S)=\frac{\pi^{M}+\alpha V_{J}(2,1)-c_{2}^{1}}{\alpha+r} .
$$

Using $V_{J}(2,1)=2 \widetilde{\pi}^{D}$, this simplifies to $2 \pi^{D}-\left(\pi^{M}-c_{2}^{1}\right)>0$. From now on, we assume this also holds so that the firms share at $(2,0)$. Similarly, the firms share at $(0,2)$ iff $2 \pi^{D}-\left(\pi^{M}-c_{1}\right)>0$. This is the same condition as the condition for sharing at $(1,2)$, so it holds. So the firms share at $(2,0)$ and $(0,2)$. We have $V_{J}(2,0)=V_{J}(0,2)=2 \widetilde{\pi}^{D}$.

The monotonicity property for firm 1 holds if and only if the firms share at $(1,0)$. The sharing condition is $V_{J}(1,1)>V_{J}(1,0 ; N S)$. The joint payoff at $(1,1)$ is

$$
V_{J}(1,1)=\frac{\alpha V_{J}(2,1)+\alpha V_{J}(1,2)-c_{2}^{1}-c_{1}}{2 \alpha+r}=\frac{4 \alpha \tilde{\pi}^{D}-c_{2}^{1}-c_{1}}{2 \alpha+r} .
$$

The joint payoff at $(1,0 ; N S)$ is

$$
V_{J}(1,0 ; N S)=\frac{\alpha V_{J}(2,0)+\alpha V_{J}(1,1)-c_{2}^{2}-c_{1}}{2 \alpha+r} .
$$

Substituting for $V_{J}(2,0)=2 \widetilde{\pi}^{D}$ and $V_{J}(1,1)$, the sharing condition simplifies to

$$
\left(2 \pi^{D}+c_{1}+c_{2}^{2}\right)+\left(c_{2}^{1}-c_{2}^{2}\right)\left(\frac{2 \alpha+r}{\alpha}\right)>0 .
$$

A sufficient condition for sharing at $(1,0)$ is that $c_{2}^{1}-c_{2}^{2}>0$. However, there are parameters in this subregion such that $c_{2}^{1}-c_{2}^{2}<0$ and the sharing condition fails. The firms do not share at $(1,0)$ and the equilibrium is not monotonic. 